Research Report

\title{
Vesicular monoamine transporter 2 regulates the sensitivity of rat dopaminergic neurons to disturbed cytosolic dopamine levels
}

\author{
Sandra Vergo ${ }^{a, 1}$, Jens Leander Johansen ${ }^{a}$, Marcel Leist ${ }^{b}$, Julie Lotharius ${ }^{a, *}$ \\ aDepartment of Molecular Biology, H. Lundbeck A/S, Ottiliavej 9, 2500 Valby, Denmark \\ ${ }^{b}$ Current address: Department of Biology, University of Konstanz, Box M657, D-78457 Konstanz, Germany
}

Keywords:

Dopamine

Parkinson's disease

Lentivirus

VMAT2

Primary mesencephalic neurons

Methamphetamine

\begin{abstract}
A B S T R A C T
An abnormal accumulation of cytosolic dopamine resulting in reactive oxygen species and dopamine-quinone products may play an important role in the rather selective degeneration of substantia nigra pars compacta (SNc) dopaminergic neurons in Parkinson's disease. The neuronal-specific vesicular monoamine transporter (VMAT2), responsible for uptake of dopamine into vesicles, has been shown to play a central role both in intracellular dopamine homeostasis and sequestration of dopaminergic neurotoxins. Direct or indirect enhancement of VMAT2 activity could therefore have neuroprotective effects by decreasing cytosolic dopamine levels. Here, we demonstrate that transfection of VMAT2 in the dopaminergic cell line, PC12, increases intracellular dopamine content, augments potassium-induced dopamine release and attenuates cell death induced by the cytosolic dopamine enhancer, methamphetamine, suggesting an enhancement in vesicular dopamine storage. In rat ventral mesencephalic cultures highly enriched for dopaminergic neurons, lentiviral delivery of recombinant VMAT2 using a neuronal-specific promoter also resulted in elevated intracellular dopamine content and neurotransmitter release after depolarization. The opposite was seen after downregulation of VMAT2 using virally delivered shRNAs. Furthermore, using this VMAT2 knockdown model, we are the first to report a direct link between enhanced cytoplasmic dopamine levels, measured following mild permeabilization of the plasma membrane using digitonin, and neurite degeneration in primary dopaminergic neurons. In conclusion, our data support the hypothesis that an increase in vesicular sequestration of dopamine by modulation of VMAT2 activity could restore neuronal function and enhance dopaminergic cell survival in conditions of dysregulated dopamine homeostasis such as Parkinson's disease.
\end{abstract}

\section{Introduction}

Dopamine, when left unsequestered in the pH-neutral, cytosolic compartment, is highly susceptible to oxidation into highly toxic dopamine-quinones and reactive oxygen species (ROS) (Graham et al., 1978; Asanuma et al., 2003). Cellular oxidative stress and formation of 5-cysteinyl-dopamine adducts, which irreversibly alter protein function, are only

\footnotetext{
* Corresponding author. E-mail address: mjl@lundbeck.com (J. Lotharius).

${ }^{1}$ Current address: RC Human immunology Unit and Department of Clinical Neurology, Weatherall Institute of Molecular Medicine, John Radcliff Hospital, University of Oxford, Oxford OX3 9DS, UK.
} 
some of the severe cytotoxic consequences of dysregulated dopamine (Barzilai et al., 2001; Berman and Hastings, 1999; Blum et al., 2001). As such, dopamine has been shown to inhibit the E3 ligase activity of parkin, a protein that protects neurons against cellular stress (Lavoie et al., 2005), and has been identified as a critical factor in the pathogenicity of protofibrillar $\alpha$-synuclein (Conway et al., 2001; Xu et al., 2002).
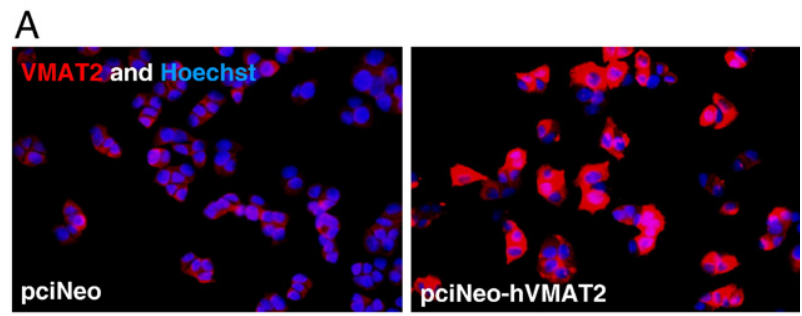

B Extracellular dopamine

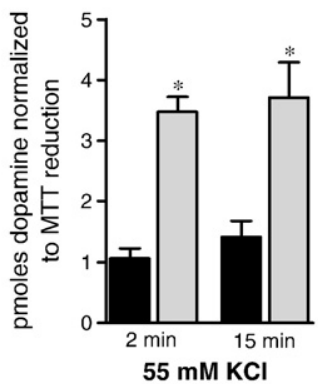

pciNeo

pciNeo-hVMAT2

C Extracellular dopamine

D Intracellular dopamine
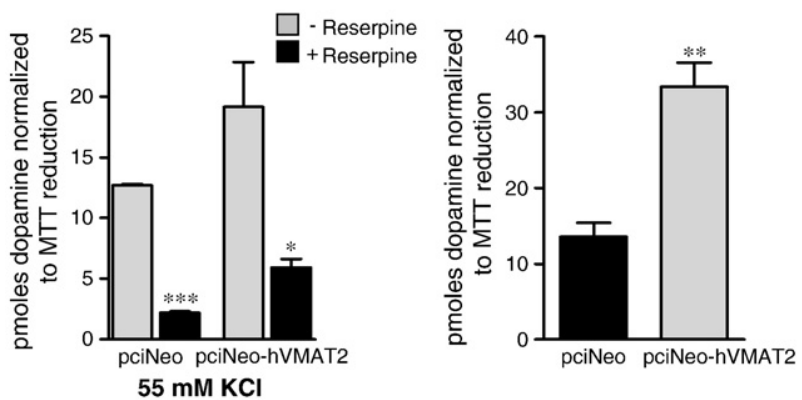

Fig. 1 - Effect of VMAT2 overexpression on cellular dopamine compartmentalization. (A) Heterologous VMAT2 expression in proliferating PC12 cells was evaluated 3 days after transfection by VMAT2 immunocytochemistry coupled with Hoechst staining. The effect of VMAT2 overexpression on cellular dopamine levels and compartmentalization cells transfected with either a human VMAT2 (hVMAT2) plasmid or an empty vector was investigated by $(B, C)$ stimulating cells for 2 or $15 \mathrm{~min}$ with a high concentration of $\mathrm{KCl}(55 \mathrm{mM})$ to induce vesicular dopamine release $(B)$ in the presence or absence of the VMAT1/2 blocker, reserpine, (C) and (D) by lysing cells using one freeze-thawing cycle in $0.1 \mathrm{mM} \mathrm{HClO}_{4}$ acid/0.01\% L-cysteine to estimate the intracellular dopamine content per well. Dopamine levels (shown in pmol) were measured by HPLC-EC and normalized to MTT reduction. Data are expressed as the mean \pm SEM of quadruplicate determinations. Bars represent three independent experiments $\left({ }^{*} \mathrm{P}<0.05,{ }^{* *} \mathrm{P}<0.01,{ }^{* * *} \mathrm{P}<0.001\right.$, paired t-test; (B, D) pciNeo vs. pciNeo-hVMAT2 or (C) -reserpine vs. + reserpine).
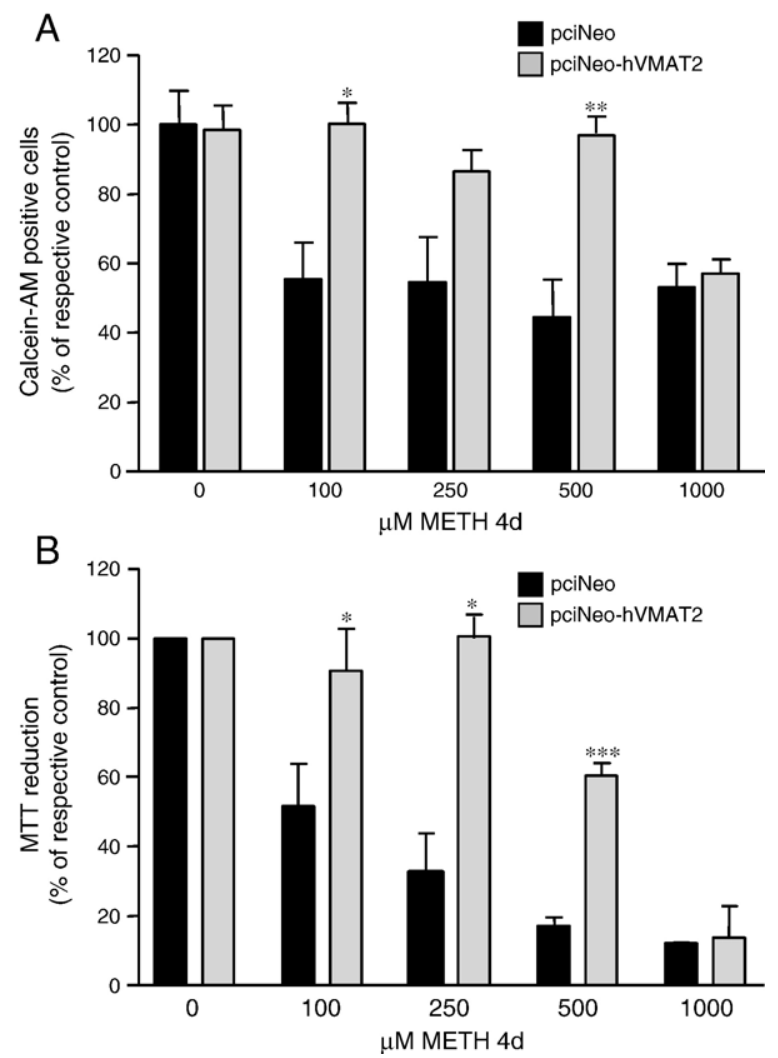

Fig. 2 - VMAT2 overexpression attenuates METH-induced neurotoxicity in differentiated PC12 cells. Cell viability was determined $4 \mathrm{~d}$ after addition of various concentrations of METH by (A) estimating the average fluorescence intensity from Calcein AM-positive cells and (B) by measuring MTT reduction. Data are expressed as mean \pm SEM of quadruplicate determinations and are shown as a percentage of respective controls within each group. Bars represent mean \pm SEM of three independent experiments in which descriptive statistics were carried out $\left({ }^{*} \mathrm{P}<0.05,{ }^{* *} \mathrm{P}<0.01\right.$, ${ }^{* * *} \mathrm{P}<0.001$, one-way ANOVA post hoc paired t-test, pciNeo vs. pciNeo-hVMAT2).

Studies using amphetamine (AMPH) or methamphetamine (METH), which are known to promote the accumulation of cytosolic dopamine, have demonstrated that dopamine-dependent oxidative stress is a necessary and sufficient mechanism for induction of nerve terminal damage and cell death in dopamine cells (Cubells et al., 1994; Larsen et al., 2002; Lotharius et al., 2005; Lotharius and O'malley, 2001). Furthermore, depletion of cellular dopamine prior to application of the parkinsonian neurotoxin, 1-methyl-4-phenylpyridinium ion $\left(\mathrm{MPP}^{+}\right)$, has been shown to result in decreased ROS formation (Lotharius and O'malley, 2000) and to attenuate dopaminergic cell death (Chen et al., 2005). Impaired dopamine storage into synaptic vesicles may therefore initiate a vicious circle causing alterations in protein function and lipid dynamics, eventually leading to neurodegeneration.

Although the pathogenic mechanisms underlying the rather selective demise of dopaminergic neurons in the substantia nigra pars compacta in idiopathic Parkinson's disease (PD) are not completely understood (Gandhi and Wood, 2005), increasing 
attention has been given to a potential dysregulation of cytoplasmic dopamine levels and dopamine-dependent oxidative stress (Sulzer, 2001; Lotharius and Brundin, 2002; Lotharius et al., 2005; Mosharov et al., 2006; Caudle et al., 2007). A key protein in intraneuronal dopamine homeostasis and vesicular turnover is the neuronal-specific vesicular monoamine transporter 2, VMAT2, which transports monoamines from the cytosol into secretory vesicles (for review (Schuldiner, 1994). Thus, VMAT2 is essential for reducing cytoplasmic dopamine accumulation after de novo synthesis and synaptic reuptake. Studies
A

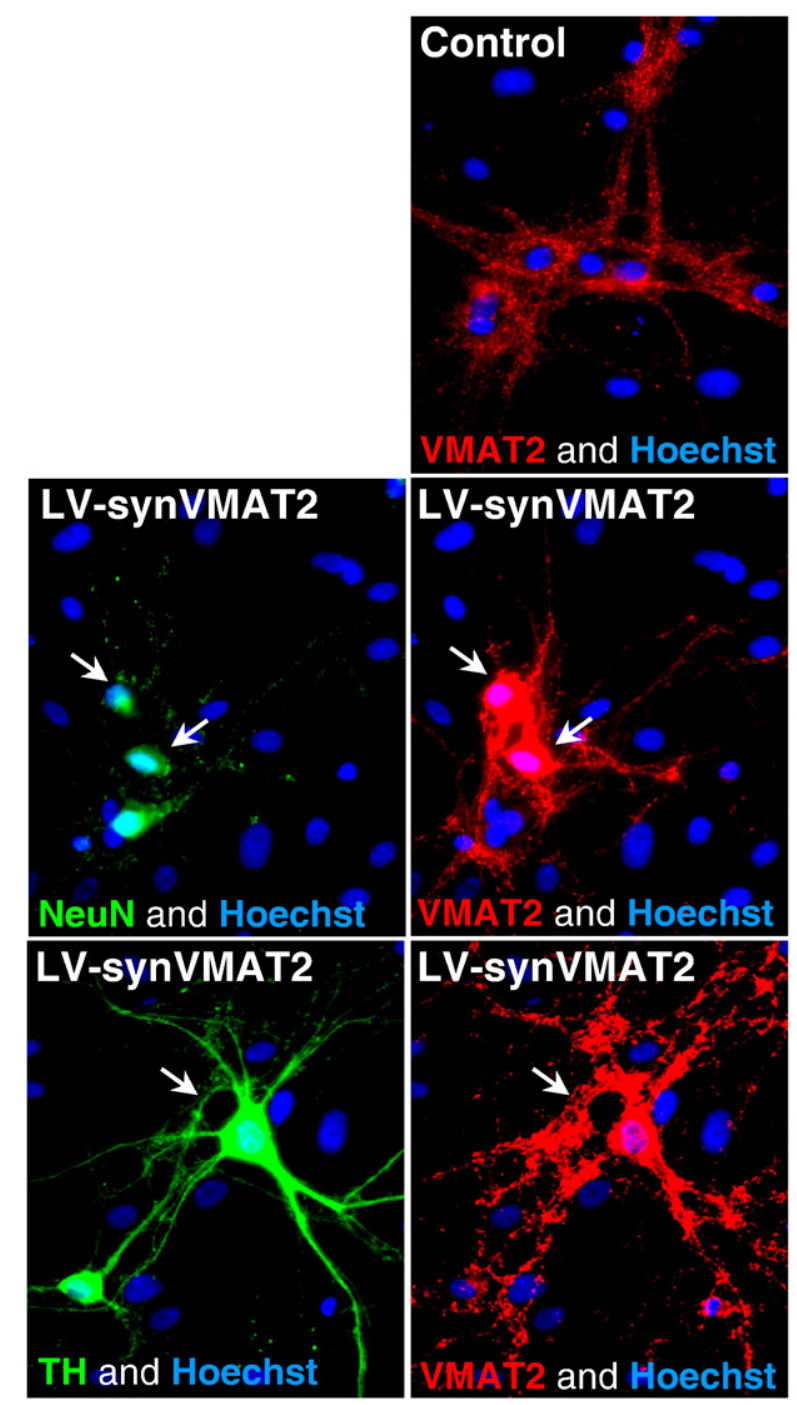

B Baseline Vesicular

Dopamine release

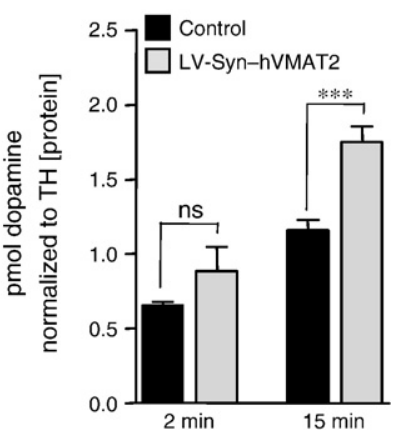

C Stimulated Vesicular
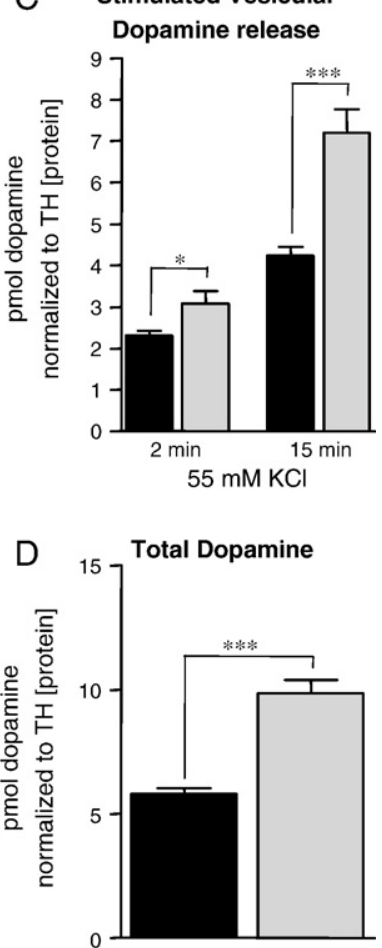

Fig. 3 - Effect of lentiviral-mediated overexpression of VMAT2 in primary rat postnatal VM cultures transduced from DIV5 to DIV15. (A) Cells were transduced from DIV5 to DIV15 with either a vector overexpressing human VMAT2 under the control of the Synapsin I promoter, LV-Syn-hVMAT2 or with a control lentiviral vector expressing EGFP. A qualitative analysis of neuronal transcriptional targeting of hVMAT2 was performed by VMAT2 immunocytochemistry coupled with Hoechst staining, and co-immunolabeling with the neuronal marker, NeuN, and the dopaminergic neuronal marker, TH. VMAT2 immunoreactivity was dramatically increased in cultures exposed to LV-Syn-hVMAT2 (transduced cells are indicated by arrows). The effect on (B) basal dopamine release, (C) $\mathrm{KCl}$-induced extracellular dopamine release (55 $\mathrm{mM} \mathrm{KCl}$ exposure for 2 or $15 \mathrm{~min}$ in the presence of $10 \mu \mathrm{M}$ mazindol to prevent release by reverse transport) and (D) total dopamine was examined by HPLC-EC. Total dopamine was calculated by adding the absolute values of extracellular dopamine released in response to $\mathrm{KCl}$ for $15 \mathrm{~min}$ plus the residual intracellular dopamine measured by lysing cells using one freeze-thawing cycle in $0.1 \mathrm{mM} \mathrm{HClO}{ }_{4}$ acid/ $0.01 \%$ L-cysteine. All values are expressed as the mean \pm SEM of quadruplicate determinations and dopamine levels (pmol) are standardized to sample collection volume and normalized to the amount of TH protein estimated by densitometry of TH Western blots prepared from untransduced/transduced cells. Bars represent the mean $\pm \mathrm{SEM}$ of three independent experiments $\left({ }^{*} \mathrm{P}<0.05,{ }^{* * *} \mathrm{P}<0.001\right.$, paired t-test, LV-Syn-EGFP vs. LV-Syn-hVMAT2-transduced cells). 
by Pothos and colleagues using heterologous overexpression of VMAT2 in primary neurons demonstrate that both quantal dopamine storage and stimulated dopamine release can be enhanced (Pothos et al., 2000; Pothos, 2002). In addition, posttranslational modifications of VMAT2, e.g. phosphorylation, have been shown to increase electrically-evoked dopamine release (Pothos, 2002), and co-incubation with vesicular small heterotrimeric G-proteins to decrease neurotransmitter uptake (Holtje et al., 2000; Holtje et al., 2003), suggesting various pathways for regulation of VMAT2 activity. Thus, enhancing VMAT2 expression and/or activity in disorders characterized by dysregulated dopamine homeostasis, such as Parkinson's disease, could exert a neuroprotective function by lowering dopaminedependent oxidative stress. In the present study, we examined the effects of modulating VMAT2 levels on dopamine compartmentalization and cell viability using primary postnatal dopaminergic neurons and the dopamine-producing cell line, PC12.

\section{Results}

2.1. Effect of VMAT2 overexpression on intracellular compartmentalization of dopamine

Initially, rat phaeochromocytoma-derived PC12 cells were used as model for a dopamine-producing cell line (Bader et al., 2002). In these cells, we expressed ectopic VMAT2 by nucleofection with a human VMAT2 cDNA (pciNeo-hVMAT2). A transfection efficiency of $\sim 35 \%$ was estimated based on the fraction of strong VMAT2-immunolabeled cells relative to the total number of Hoechst-positive cells. VMAT2 protein was located throughout the whole cytoplasm (Fig. 1A).

The effect of VMAT2 overexpression on vesicular dopamine content was measured functionally by stimulating exocytotic release of dopamine via plasma membrane depolarization with high potassium ion concentration in the extracellular medium. In response to high $\mathrm{KCl}$, extracellular DA levels were increased 3-fold in VMAT2-expressing cultures compared to pciNeo-transfected cultures when measured 3 days posttransfection (Fig. 1B). Potassium-stimulated release from the latter was most likely due to endogenous VMAT1 expression (Bader et al., 2002). The release experiments were performed in the presence of mazindol, a specific DAT inhibitor, to block any potential dopamine release by reverse transport through the DAT and allow for the specific measurement of vesicular release (Leviel, 2001). Prior to stimulation, cells were incubated for $15 \mathrm{~min}$ in buffer containing mazindol to ensure blockade of DAT sites. Furthermore, to ensure that potassium-induced release was indeed VMAT2-dependent, we examined the effect of reserpine, an inhibitor of VMAT1/2, in VMAT2 overexpressing cultures. As expected, reserpine blocked $>80 \%$ of stimulated release (Fig. 1C). VMAT2 overexpression also increased

A

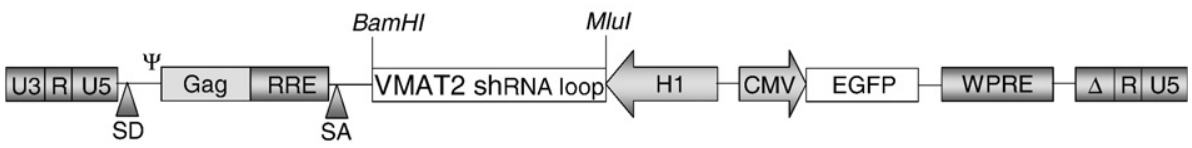

\section{B}
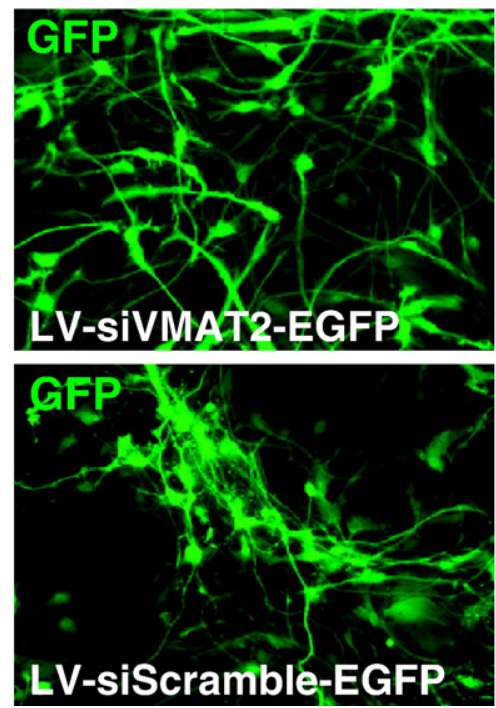

C
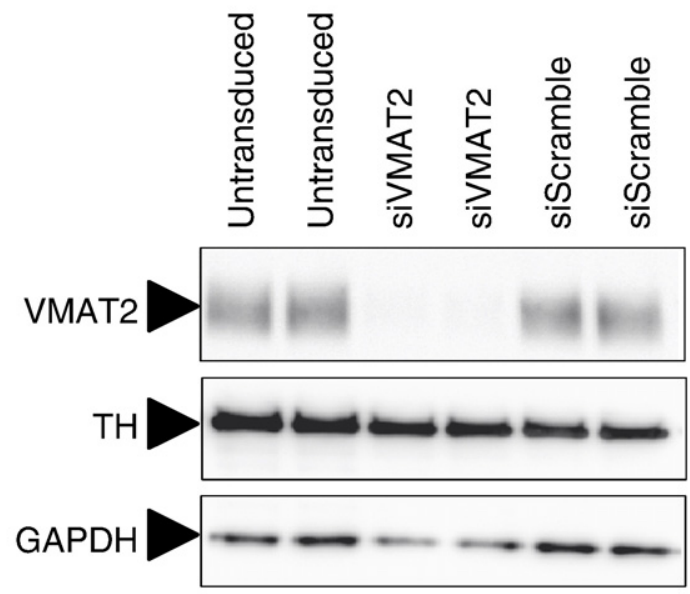

Fig. 4 - Downregulation of endogenous VMAT2 expression using lentiviral-mediated expression of silencing short hairpin RNA (shRNAs) in primary postnatal rat VM cultures. (A) A schematic representation of the LV-rVMAT2-shRNA-CMV-EGFP expressing vector is shown where CMV: cytomegalovirus derived promoter; Gag: a truncated version of the minimal structural protein; H1: polymerase III promoter; LTR: 3' or 5' long terminal repeat; SD: Splice donor site for splicing of the targeted transcript until SA: Splice acceptor site; $\Psi$ : packaging signal; RRE: REV response element; WPRE: Woodstock postregulatory response element. (B) Day 5 primary postnatal VM cultures were used for lentiviral infection and delivery of the sivMAT2 silencing cassette or an internal control. (C) Western blot analysis was carried out 8-10 days post-transduction to assess downregulation of VMAT2 protein. TH was also immunoprobed to ensure that VMAT2 downregulation did not lead to a loss of dopamine neurons, which might explain a downregulation in VMAT2. GAPDH was used as a loading control. Samples were loaded in duplicate. 
the total intracellular dopamine content (Fig. 1D). Since vesicles serve as the main intracellular storage compartment for monoamines, the observed increase in total cellular dopamine content is likely to reflect an increased cellular capacity for vesicular monoamine uptake.

All our data are normalized to the number of viable cells within the same dish from which dopamine was measured to ensure that the effect observed was not solely a result of in creased cell survival. The number of viable cells was estimated by the MTT reduction capacity in each respective culture. In summary, these results suggest that the heterologous VMAT2 expression is functional in transfected PC12 cells and results in enhanced intracellular dopamine storage capacity.

2.2. VMAT2 overexpression attenuates METH-induced cell death in differentiated PC12 cells

Next, we examined whether increased vesicular sequestration of dopamine resulting from overexpression of VMAT2 would protect dopaminergic PC12 cells from the drug methamphetamine (METH), known to increase the cytoplasmic levels of dopamine. After transfection, the cells (control vector or VMAT2) were differentiated with NGF for 3 days to a neuronal phenotype, and then exposed to various concentrations of METH. Cell viability was assessed both by quantification of average fluorescence intensity from cells stained with the fluorescent viability dye Calcein AM (Fig. 2A) and by measuring MTT reduction capacity (Fig. 2B). In control cells, METH led to significant cell death within 4 days with an $\mathrm{EC}_{50}$ of $80 \mu \mathrm{M}$ (calculated on the basis of cellular MTT reduction capacity) whereas in cell cultures expressing recombinant hVMAT2, a 6-fold attenuation of this response was observed (EC $50 \sim 500 \mu \mathrm{M})$. The higher viability of VMAT2-expressing PC12 cells exposed to 100-500 $\mu \mathrm{M}$ METH shows that increased vesicular sequestration of dopamine can protect dopaminergic cells from the detrimental effects of enhanced cytosolic dopamine load induced by METH. These data are consistent with the hypothesis that VMAT2 mediates its neuroprotective effect via an increase in vesicular sequestration of dopamine.

\subsection{Transcriptional targeting of hVMAT2 expression in} primary postnatal rat VM dopaminergic cultures using lentiviral delivery results in increased dopamine release and content

In order to evaluate the role of modulating VMAT2 protein levels on intraneuronal dopamine compartmentalization in primary dopaminergic neurons, postnatal rat VM dopaminergic neuronal cultures were used as a model system. Advantages of postnatal-derived cultures over the commonly used embryonic cultures are primarily the high percentage of dopaminergic neurons (20-70\%) within the total neuronal population in addition to their more mature phenotype, i.e. higher expression of TH and DAT, and demonstration of a robust D2-mediated auto-receptor response already after 2 days in culture (Rayport et al., 1992). This high resemblance to their in vivo counterparts was seen as a significant advantage in the present study aimed at testing the role of increased vesicular transport in dopamine homeostasis.

Endogenous VMAT2 co-localized with neuronal processes, and staining was dramatically increased after 10 days after lentiviral transduction with a recombinant hVMAT2 construct (Fig. 3A). Given the high expression of EGFP in non-neuronal cells using a CMV promoter-containing lentivirus (data not shown), the neuronal-specific promoter Synapsin I (Syn) was
A
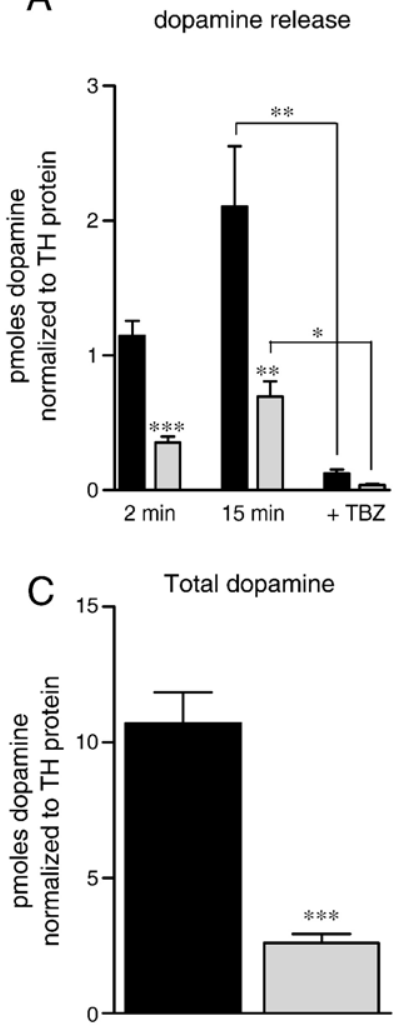

B Stimulated dopamine release

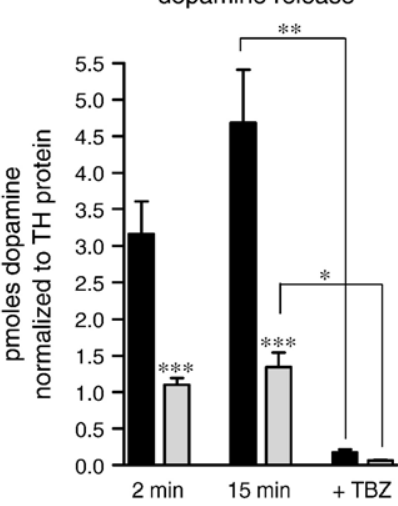

Fig. 5 - Silencing endogenously expressed VMAT2 in primary postnatal rat dopaminergic cultures impairs basal and stimulation-induced dopamine release and lowers neurotransmitter content. Day 5 primary postnatal VM cultures were used for lentiviral infection and delivery of the siVMAT2 silencing cassette or an internal control. On day 10 post-transduction (DIV15), (B) basal dopamine release, (C) $\mathrm{KCl}$-induced extracellular dopamine release $(55 \mathrm{mM} \mathrm{KCl}$ for 2 or $15 \mathrm{~min}$ in the presence of $10 \mu \mathrm{M}$ mazindol) and (D) total, intracellular dopamine (collected by lysing cells in $0.1 \mathrm{mM} \mathrm{HClO}_{4}$ acid/0.01\% L-cysteine) were measured by HPLC-EC. The significantly lower extracellular concentration of dopamine estimated in the presence of the VMAT2 inhibitor, tetrabenazine (TBZ; $10 \mu \mathrm{M}$ ), confirmed that the exocytotic process was VMAT2 dependent. All values are expressed as the mean \pm SEM of quadruplicate determinations and dopamine levels (pmol) are standardized to sample collection volume and normalized to the amount of TH protein estimated by densitometry of TH Western blots prepared from untransduced/transduced cells. Bars represent the mean $\pm \mathrm{SEM}$ of three independent experiments $\left({ }^{*} \mathrm{P}<0.05,{ }^{* *} \mathrm{P}<0.01,{ }^{* * *} \mathrm{P}<0.001\right.$, paired t-test, stars placed over bars represent significant difference between LV-siScramble-EGFP vs. LV-siVMAT2-EGFP, and stars above lines connecting different groups, a difference between those conditions). 
used to transcriptionally target hVMAT2 specifically to the neuronal population. This was confirmed by double immunofluorescence staining using both a VMAT2-antibody together with either NeuN or TH as neuronal and dopaminergic neuronal markers, respectively (Fig. 3A). Cells transduced with an LV-SynEGFP vector were used as a control for all experiments. At low $\mathrm{KCl}$ concentrations, neurons were found to be slightly excitable, resulting in some exocytotic release of dopamine measured in the extracellular medium in the presence of mazindol using HPLC-EC (Fig. 3B). However, overexpression of recombinant hVMAT2 resulted in significantly higher basal dopamine release after 15 min of equilibration in a low potassium buffer compared to control (Fig. 3B). However, the difference to control cells was particularly pronounced after stimulation with high $\mathrm{KCl}$, and more prominent after 15 min vs. 2 min of stimulation (Fig. 3C). The total, intracellular dopamine content in the primary VM culture system was also increased as a result of heterologous VMAT2 expression (Fig. 3D). Taken together, these results indicate that in primary dopaminergic neurons, vesicular storage capacity is not saturated, but rather leaves ample space for regulation by augmented VMAT2 expression levels.
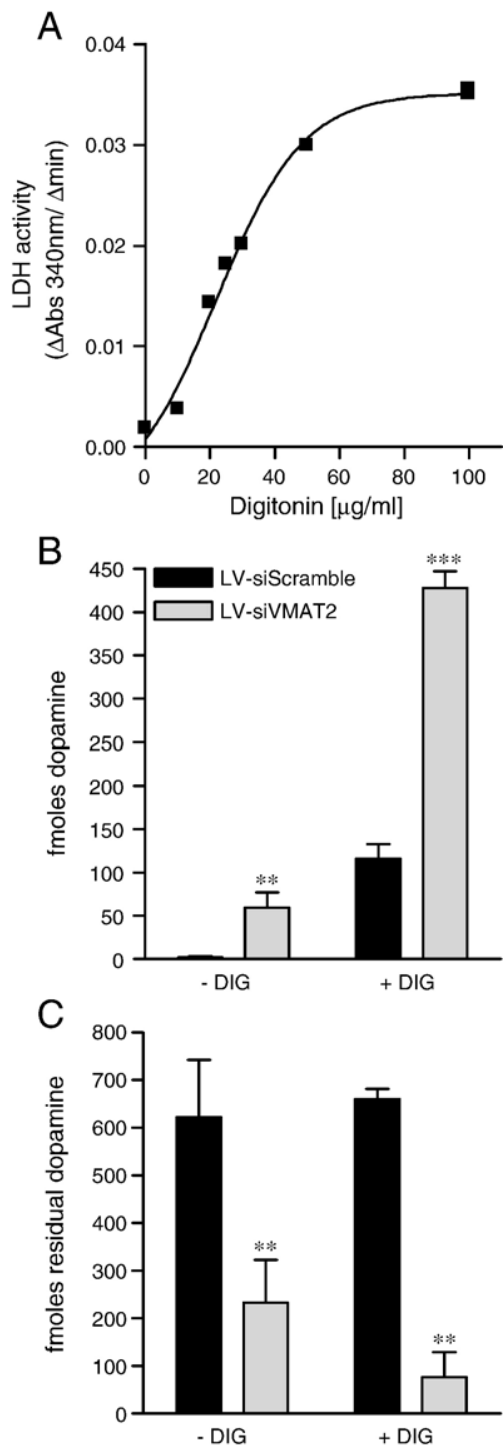

2.4. Silencing of endogenously expressed VMAT2 in primary postnatal rat VM dopaminergic neurons results in lower vesicular and total dopamine content and increased cytosolic dopamine

As an alternative approach to generate two diametrically different levels of VMAT2 expression, we made use of the endogenously high constitutive expression of the transporter in primary postnatal rat VM neurons in addition to knockdown of this target via lentiviral delivery of VMAT2-targeting shRNAs. Such an attempt has never been undertaken in primary postnatal dopaminergic neuron-enriched cultures.

A dual lentiviral vector (LV-siVMAT2-EGFP) co-expressing a rat VMAT2 targeting shRNA and the reporter gene EGFP under the direction of the CMV promoter was used to silence endogenous VMAT2 in postnatal cultures (Fig. 4A). Based on GFP-positive cell counts, a $\sim 70 \%$ transduction efficiency (relative to all the cells in the culture) was obtained after 10 days of transduction (Fig. 4B), leading to a dramatic reduction in VMAT2 protein at this time point (Fig. 4C). Western blots for TH in primary postnatal VM cultures infected with LV-siVMAT2-EGFP did not show a significant decrease in TH expression, suggesting that the reduction in endogenous VMAT2 protein did not result from a reduction in TH-positive neurons (Fig. 4C).

Basal and potassium-stimulated dopamine release was found to be decreased by $50-70 \%$ in neurons with reduced expression levels of VMAT2 (transduced from DIV5 to DIV15) after 2 and 15 min of high $\mathrm{KCl}$ (Figs. 5A, B). In agreement with this finding and with what has previously been shown in VMAT2 knockout mice (Fon et al., 1997; Gainetdinov et al., 1998), silencing VMAT2 resulted in a decrease in total dopamine content (Fig. 5C). The absolute amount of dopamine was normalized to the amount of $\mathrm{TH}$ protein estimated by densitometry of TH Western blots from the same preparation (to make sure that no artifacts occurred due to a loss of cell

Fig. 6 - Silencing endogenously expressed VMAT2 in primary postnatal rat dopaminergic cultures increases cytoplasmic dopamine levels. (A) The optimal concentration of the gentle, cholesterol-binding detergent, digitonin, needed to specifically permeabilize the plasma membrane was estimated by measuring the extracellular levels of LDH, a cytosolic enzyme. (B) Postnatal VM cultures transduced for 10 days with either $\mathrm{LV}$-siScramble-EGFP or LV-siVMAT2-EGFP were first exposed to buffer with mazindol (MAZ) and AMPH for $10 \mathrm{~min}$ to increase cytosolic dopamine levels (data not shown). The buffer was collected and cells exposed to a buffer with MAZ only (-DIG) or a buffer with $40 \mu \mathrm{g} / \mathrm{ml}$ digitonin and MAZ (+DIG) for $7 \mathrm{~min}$ on ice in order to extract the cytosolic dopamine fraction. The total amount of dopamine in the supernatant was then measured using a dopamine ELISA kit. After removal of the \pm digitonin-containing solution, cells were lysed in $0.1 \mathrm{mM}$ $\mathrm{HClO}_{4}$ acid/0.01\% L-cysteine by freeze-thawing to measure residual dopamine content (C), also by dopamine ELISA. Respective buffers for each condition were run in the dopamine ELISA and gave no background. Data are expressed as fmol dopamine per well. Bars represent the mean \pm SEM of a representative experiment conducted three times $\left({ }^{* *} \mathrm{P}<0.01,{ }^{* * *} \mathrm{P}<0.001\right.$, paired t-test, LV-siScramble-EGFP vs. LV-siVMAT2-EGFP). 
viability). The extracellular dopamine release was nearly completely abolished by co-treatment with the VMAT2specific inhibitor, tetrabenazine (TBZ) (Figs. 5A, B). These data suggest that the observed reduction in total dopamine reflects a decrease in vesicular dopamine storage.

Next we examined how silencing endogenous VMAT2 protein expression would affect the levels of cytoplasmic dopamine in primary postnatal dopaminergic neurons. For this purpose, cells were subjected to a digitonin extraction procedure and the dopamine released from the cells was measured using a dopamine ELISA due to an unexpected interference of digitonin with the electrochemical detection procedure and the high sensitivity afforded by newly available ELISA methods. In order to simulate a pathological state of increased cytoplasmic dopamine, cells were challenged with AMPH. To prevent the potential reverse transport of dopamine and thus "trap" cytosolic dopamine inside the cell, cultures were continuously exposed to the DAT inhibitor, mazindol. Cytosolic dopamine was then extracted using a mild, selective permeabilization of the plasma membrane with the steroid glycoside, digitonin (Fiskum et al., 1980).

Using this digitonin-based permeabilization technique we extracted the cytosolic dopamine fraction from rat postnatal VM neurons transduced with VMAT2 overexpressing or VMAT2 silencing lentiviral vectors. To find the optimal concentration of digitonin that would preclude complete plasma membrane permeabilization and the potential rupture of intracellular membranes, i.e. synaptic vesicles, we measured the activity levels of lactate dehydrogenase (LDH), a cytosolic protein, in the extracellular milieu in response to different concentrations of digitonin (Fig. 6A). Complete disruption of the plasma membrane was obtained after application of $70-100 \mu \mathrm{g} / \mathrm{ml}$ digitonin since treatment of cells with $0.1 \%$ Triton-X, a strong detergent, led to similar levels of extracellular LDH as did these high concentrations of digitonin (data not shown). Thus, $40 \mu \mathrm{g} / \mathrm{ml}$ digitonin was deemed an optimal concentration for extracting the cytosolic dopamine pool into the extracellular milieu. Indeed, lysis of cells after digitonin treatment using $0.1 \mathrm{M} \mathrm{HClO}_{4}$ confirmed that intracellular membranes had not been ruptured since residual dopamine levels in cells treated with buffer alone or buffer with $40 \mu \mathrm{g} / \mathrm{ml}$ digitonin were identical (Fig. 6B). Downregulation of VMAT2 in primary neurons transduced with a VMAT2-targeting shRNA resulted in a 3.7-fold increase in cytoplasmic dopamine in cells following AMPH exposure (Fig. 6B). In cells treated with mazindol-containing buffer alone, i.e. minus digitonin, a small increase in extracellular dopamine could be detected in low VMAT2 expressing cells. Interestingly, we observed a dramatic decrease in intracellular dopamine levels in cells transduced with the shVMAT2 virus as shown previously in Fig. 5C, but again, no difference in residual dopamine content between the minus digitonin and plus digitonin conditions for each experimental group, indicating this reduction was not due to a disruption of vesicular membranes by digitonin. Using the VMAT2 overexpressing lentiviral vector, we did not observe any difference in cytosolic dopamine levels between LV-Syn-VMAT2 and

\section{A Neuritic TH immunofluorescence}

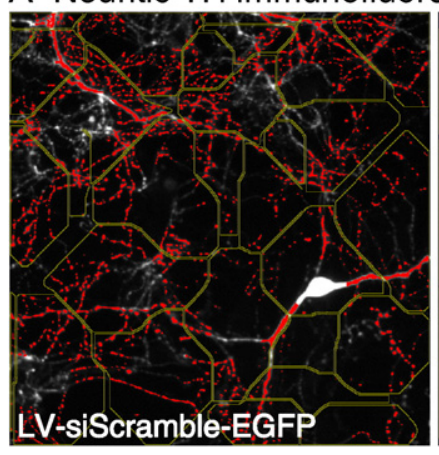

B

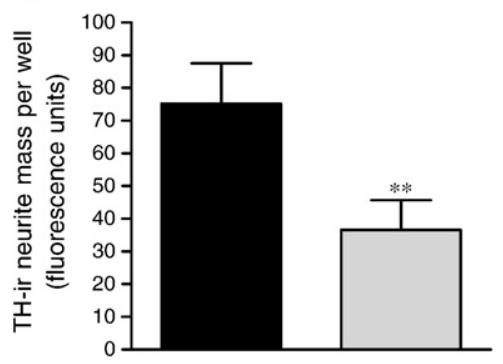

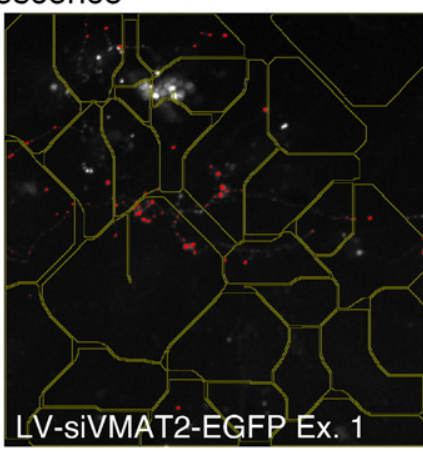

C

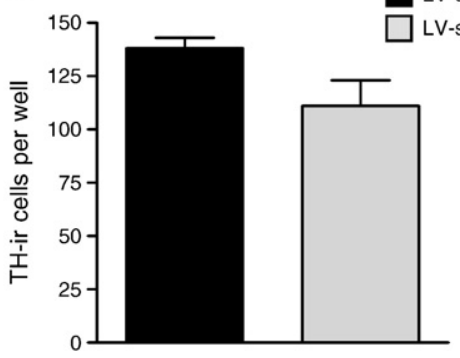

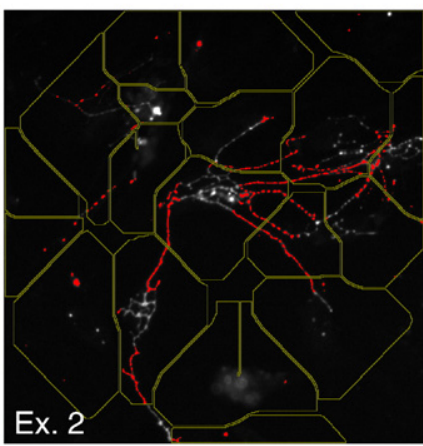

LV-siScramble-EGFP LV-SIVMAT2-EGFP

Fig. 7 - Effect of VMAT2 downregulation on TH-positive neurite mass and neuron number in primary postnatal rat VM cultures. (A) Neuritic TH immunofluorescence in DIV21 old primary postnatal VM dopaminergic culture transduced with either LV-siVMAT2-EGFP or LV-siScramble-EGFP. (B) The neurite mass was estimated by a GPCR BioApplication from Cellomics using a Cellomics ArrayScan HCS System to quantify fluorescent TH-immunoreactivity (TH-ir) shown in red in a distinct area/domain outlined in green corresponding to each neuron. The cell body immunofluorescence was extracted from the analysis to allow measurement of neurites only. Bars represent the mean \pm SEM of two independent experiments (**P $<0.01$, paired $t$-test). (C) The number of TH-ir neurons was quantified by counting the number of TH-positive cell bodies in the same wells as those used to estimate neurite mass. Bars represent the mean \pm SEM of two independent experiments $(P>0.05$, paired $t$-test). 
control vector (data not shown). In summary, these data strongly support the hypothesis that dopaminergic neurons with impaired vesicular storage capacity exhibit an abnormal accumulation of dopamine in the cytoplasm.

\subsection{Silencing of VMAT2 results in loss of TH-positive neurite mass but not neuron number}

Finally we examined the functional consequences of altered VMAT2 expression levels on dopaminergic cell viability in fully differentiated, long-term cultures (3 week old cultures). Reduced expression levels of VMAT2 (Mooslehner et al., 2001) or pharmacological inhibition of the transporter (Mosharov et al., 2003) has previously been demonstrated to result in higher dopamine turnover thereby exposing neurons to dopamine-dependent oxidative stress and dopamine-quinone formation. We set up a method to identify dopaminergic neurites, based on the staining of these structures with an antibody against tyrosine hydroxylase (TH) and subtraction of the cell body area using a specialized algorithm (see Materials and Methods). Using a Cellomics Array Scanner, these data were quantified in lentivirus-transduced primary postnatal rat VM cultures. We observed a profound, $>60 \%$ decrease in TH-positive neurite mass in primary neurons expressing low levels of VMAT2 compared to internal control cultures with normal VMAT2 expression (Figs. 7A, B). No loss in actual THpositive cell bodies was observed (Fig. 7C). Thus, VMAT2 deficiency seems to have profound implications, especially in older neuronal cultures, where dopaminergic cells are chronically exposed to endogenous oxidative stress (Figs. 7A, B).

\section{Discussion}

Due to their low $\mathrm{pH}$, vesicles represent a non-oxidative compartment suitable for intracellular dopamine storage (Eisenhofer et al., 2004). By sequestering dopamine into vesicles, VMAT2 plays an important role in controlling presynaptic neurotransmission and in keeping the cytosolic level of potential exogenous and endogenous dopaminergic neurotoxins within a tightly regulated range (Liu et al., 1992; Erickson et al., 1992; Liu and Edwards, 1997). Two separate studies evaluating the functional effect of VMAT2 overexpression have demonstrated that VMAT2 activity affects both vesicular storage and the frequency of exocytotic release events in primary dopaminergic and hippocampal neuronal cultures (Pothos, 2002; Pothos et al., 2000). In agreement with these studies, we find that stimulation-dependent vesicular release was increased in VMAT2-expressing PC12 cells and in primary postnatal rat VM dopaminergic neurons overexpressing human VMAT2. In brief, these data indicate a high buffering capacity for neurotransmitter storage in the dopaminergic system, offering an interesting prospect for further exploration of vesicular transmitter uptake modulation as potential drug targets for PD.

In order to assess the impact of overexpression of VMAT2 on cell viability in compromised dopaminergic neurons, we used METH as a cellular model of intracellular dopamine toxicity. AMPH and its derivatives have been shown to perturb cytosolic catecholamine homeostasis (Lotharius and Brundin, 2002).
Concentrations in the $100-\mu \mathrm{M}$ range are sufficient to collapse $\mathrm{pH}$ gradients and prevent VMAT2-mediated uptake of dopamine (Sulzer et al., 1995; Mundorf et al., 1999). Even though DATmediated reverse transport of dopamine into the extracellular space would be expected to lower cytoplasmic dopamine load (Sulzer et al., 1995; Jones et al., 1999), transient accumulation of this labile catecholamine in the cytoplasm results in the generation of cytotoxic, oxidative metabolites (Cubells et al., 1994; Lavoie and Hastings, 1999; Larsen et al., 2002; Miyazaki et al., 2006). In addition to promoting redistribution from vesicular compartments to the cytosol, METH stimulates tyrosine hydroxylase (TH) activity, which has been shown to further enhance intracellular dopamine synthesis (Larsen et al., 2002), and inhibits monoamine oxidase (MAO) (Egashira and Yamanaka, 1993), thus favoring autooxidation of dopamine.

Neurotoxicity by METH typically involves disintegration of neuronal processes but not a loss of cell viability (Larsen et al., 2002; Cubells et al., 1994; Lavoie and Hastings, 1999; Miyazaki et al., 2006), unless co-stressors like iron are added (Lotharius et al., 2005). In differentiated PC12 cells, however, relevant concentrations of METH led to significant cell death, which could be due to the higher overall dopamine content in these cultures. In this cell line, VMAT2 overexpression attenuated METHinduced toxicity supporting the hypothesis that increased vesicular sequestration can be neuroprotective. Similarly, VMAT2 overexpression has been shown to protect another dopaminergic cell line, MN9D, against $\mathrm{MPP}^{+}$-induced toxicity (Chen et al., 2005). In addition to its effects on mitochondrial respiration, this neurotoxin has also been shown enhance cytosolic accumulation of dopamine leading to oxidative stress (Lotharius and O'malley, 2000). CHO cells expressing high levels of VMAT2 are likewise resistant to this toxin (Liu et al., 1992), suggesting that the more transporters a cell contains, the better it can buffer the toxic consequences of dopamine-redistributing insults. In agreement with previous studies, we were unable to elicit significant cell death even with high concentrations of METH (e.g. $1 \mathrm{mM}$ ) in primary postnatal rat dopaminergic neurons.

The relative resistance of young, healthy VM neurons to METH may signal a tightly regulated homeostatic machinery where VMAT2, TH and MAO act in concert to maintain cytosolic catecholamines at a stable, low level. This hypothesis is supported by unsuccessful attempts at detecting cytosolic dopamine in these neurons using highly sensitive techniques such as intracellular patch electrochemistry (IPE) (David Sulzer, personal communication). This phenomenon is not seen in the peripheral noradrenergic system, for instance, where Mosharov and colleagues (2003) report basal cytosolic catecholamines in the low micromolar range in cultured chromaffin cells using IPE. However, in an aged or diseased central neuron where intracellular dopamine homeostasis might be dysregulated, a process we attempted to mimic with METH and which might be plausible in $\mathrm{PD}$, increasing vesicular dopamine uptake may have a great impact on cell survival. As we were unable to test this hypothesis directly in our postnatal culture system since cells were resistant to METH, we opted for using siRNA-mediated downregulation of VMAT2 to achieve an indirect proof-of-concept. We hypothesized that lowering VMAT2 expression in these cells would enhance METH-induced toxicity by increasing cytosolic dopamine accumulation, a notion. Previous studies have shown that 
postnatal VM neuronal cultures derived from VMAT2 heterozygous (+/-) or homozygous (-/-) mice are more susceptible to METH-induced neurite degeneration, oxyradical formation and accumulation of dopamine-quinones (Larsen et al., 2002).

Using lentiviral expressing VMAT2-targeting shRNAs to silence endogenous VMAT2 in primary postnatal rat VM neurons we investigated the role of VMAT2 on intraneuronal dopamine homeostasis and cell viability. Pharmacological inhibition of VMAT2 in vitro has been demonstrated to result in increased lipid peroxidation and protein-bound quinones (Choi et al., 2005), strong indicators of elevated cytoplasmic dopamine. Indeed, the cytosolic level of catecholamines was found to be significantly increased in chromaffin cells as a result of VMAT2 inhibition (Mosharov et al., 2003). Furthermore, pharmacological or genetic inhibition of VMAT2 activity in vivo has been shown to enhance the toxicity of MPTP (Takahashi et al., 1997; Gainetdinov et al., 1998; Mooslehner et al., 2001) and METH (Fumagalli et al., 1999), models of PD believed to evoke an abnormal accumulation of dopamine. Increased dopamine turnover together with reduced phosphorylation of $\mathrm{TH}$ at the residue associated with catechol feedback inhibition has also been demonstrated in brain of VMAT2-deficient KA1 mice expressing $\sim 5 \%$ of WT VMAT2 protein levels (Mooslehner et al., 2001; Colebrooke et al., 2006), suggesting an increase in cytosolic dopamine. In line with these findings, the present study is the first to demonstrate a direct link between downregulation of VMAT2 and a rise in cytoplasmic dopamine concentration in primary neurons, accompanied by a loss in intracellular neurotransmitter storage. Based on the assumption that a disruption in intracellular dopamine homeostasis could be responsible for the increased vulnerability of nigral dopaminergic neurons in $\mathrm{PD}$, this model recapitulates a disease condition and could be used for future mechanistic studies aimed at finding potential therapeutic targets for PD.

In primary postnatal rat VM cultures with downregulated levels of VMAT2, we observed a drastic reduction in the number and length of TH-positive neurites, possibly caused by the cytotoxic effects of increased cytosolic dopamine load. As the cells are transduced with lentivirus before processes are fully extended the differences seen could in principle be due to effects on growth as well as degeneration. Therefore, control cultures (untransduced) were stained for $\mathrm{TH}$ immunoreactivity at different ages and were seen to show similar neurite mass to LV-siScramble-EGFP transduced cultures (data not shown). Even though no loss of nigral TH neurons has been detected in one study looking at VMAT2-deficient mouse at up to 24 months of age, terminal function may still be highly impaired as one explanation for the low level of striatal dopamine in these animals (Colebrooke et al., 2006). In a separate study using VMAT2-deficient mice, an age-dependent increase in oxidized metabolites of dopamine has been correlated to a progressive loss in DAT immunoreactivity, axonal degeneration, and a $26 \%$ reduction in $\mathrm{TH}$-positive cells were detected at 24 months of age (Caudle et al., 2007). In addition, apoptosis induced via a mitochondria-dependent cascade involving the activation of caspase- 9 and the apoptosome complex is enhanced in cerebral cortex from VMAT2 deficient mice during early postnatal developmental (P1-P3) (Stankovski et al., 2007). Even though apoptotic mechanisms underlying dopamine dysregulation is not the focus of this paper, it has been shown by others that the stress-inducible transcription factor NF-kappa B can be activated by intracellular dopamine, a process resistant to antioxidant protection (Weingarten et al., 2001). In this way, a low expression of VMAT2 could trigger apoptotic cascades via the increase in cytosolic dopamine. Together, these studies clearly indicate an important influence of VMAT2 expression on dopaminergic cell survival.

Additional studies suggest that accumulation of cytosolic dopamine resulting from $\alpha$-synuclein mutations, which have been linked to familial PD, could contribute to disease pathogenesis (Lotharius et al., 2002; Mosharov et al., 2006). Changes in VMAT2 activity together with vesicular transmitter leakage prompted by cytosolic dopamine-stabilized $\alpha$-synuclein protofibrils (Conway et al., 2001; Rochet et al., 2004) have been suggested as possible mechanisms involved (Lotharius et al., 2002, Mosharov et al., 2006; Caudle et al., 2007). Our data support the notion that dysregulated intracellular dopamine homeostasis could be a central pathogenic event making dopaminergic neurons selectively vulnerable in PD. This hypothesis is already gaining significant attention as substantial progress has been made in evaluating the potential pharmacological modulation of VMAT2 as a therapeutic, disease modifying target for PD (reviewed by Zheng et al., 2006). Furthermore, human data support a neuroprotective role of VMAT2. For example, regulatory compensation of VMAT2 expression has been found in PD where ventral tegmental dopaminergic neurons spared in this disorder harbor higher levels of this transporter (Miller et al., 1999). Also, a recent study on structural polymorphisms in the gene encoding VMAT2 reported that haplotypes displaying increased transcriptional activity are protective against PD in females (Glatt et al., 2006). The limited success of several neuroprotective clinical trials in PD targeting downstream disease processes including apoptosis and oxidative stress (Johnston and Brotchie, 2006), suggests that aiming for an early pathogenic event such as dysregulation of cytoplasmic dopamine storage may hold great promise for altering the course of the disease.

\section{Experimental procedures}

\subsection{Plasmids and chemicals}

pciNeo was purchased from Promega, USA (7011 bp). pciNeohVMAT2 was generated at $\mathrm{H}$. Lundbeck A/S, Department of Molecular Biology. The human VMAT2 (hVMAT2) cDNA sequence (GenBank accession no. BC108927) was excised from the original plasmid pcdSP6/T7 (a kind gift from Jeff Erickson; Erickson and Eiden, 1993) and inserted into SalI/XhoI sites of the pciNeo plasmid vector. Methamphetamine was obtained from Lipomed (Arleshein, Switzerland). Tetrabenazine was obtained from Fluka (Buch, Switzerland). Reserpine (R0875), mazindol (M2017) and amphetamine (A5880) were all obtained from Sigma (Brøndby, Denmark).

\subsection{Cell culture and transfections}

PC12 cells (purchased from American tissue culture collection, CRL-1721) were maintained in proliferation medium 
consisting of Dulbecco's modified Eagle's medium (DMEM, Gibco, 61965-026), 10\% heat-inactivated horse serum (HI-HS; Gibco, 16050-122), 5\% heat-inactivated fetal calf serum (HIFCS), $1 \%$ sodium pyruvate (Gibco, 11360-039), $100 \mathrm{U} / \mathrm{ml}$ penicillin and $100 \mu \mathrm{g} / \mathrm{ml}$ streptomycin (PenStrep). Prior to plating, cell culture multidishes (Nunc, Denmark) were coated with $50 \mathrm{mg} / \mathrm{L}$ poly-L-lysine (PLL) overnight at RT. For cell survival experiments, the AMAXA-mediated cell nucleofection technique was used (Cell Line Nucleofector Kit V, VCA1003, AMAXA Biosystems, USA) for cell transfection. In brief, $2 \times 10^{6}$ cells were centrifuged at $90 \times g$ for $5 \mathrm{~min}$, and resuspended in $100 \mu$ l Amaxa nucleofection solution before electroporation as per the manufacturer's instructions. The following nucleofection conditions were performed: (1) Amaxa control (0 $\mu \mathrm{g}$ DNA), (2) $3 \mu \mathrm{g}$ pciNeo-hVMAT2 and (3) $3 \mu \mathrm{g}$ pciNEO empty vector. The Amaxa program U-29 was run, followed by adding $500 \mu \mathrm{l}$ pre-warmed PC12 differentiation medium (DMEM supplemented with $1 \% \mathrm{HI}-\mathrm{HS}, 1 \%$ sodium pyruvate and PenStrep, and $100 \mathrm{ng} / \mathrm{ml}$ NGF (Invitrogen, 13290-010). Nucleofected PC12 cells were then plated in differentiation medium at a density of $1.2 \times 10^{4} \mathrm{cells} / \mathrm{cm}^{2}$ in 96 -well plates.

For dopamine release experiments, $2.7 \times 10^{4} \mathrm{cells} / \mathrm{cm}^{2}$ were plated in 48-well dishes in proliferation media without PenStrep and transfected the following day. Opti-MEM ${ }^{\circledR}$ was used to prepare dilutions of DNA (pciNeo/pciNeo-hVMAT2) using $0.4 \mu \mathrm{g} D N A / \mu l$ Lipofectamine 2000 (Invitrogen, 11668019). After a 3.5 -h incubation period with the DNA-Lipofectamine complexes, the medium was replaced with fresh proliferation medium and transgene expression allowed for an additional $72 \mathrm{~h}$ before measurement of stimulated dopamine release and intracellular dopamine content. For all experiments, half of the medium was changed every second day until the initiation of the experiment.

Primary postnatal rat ventral mesencephalic (VM) dopamine neuronal cultures were prepared from day 1-3 postnatal rats in two stages using a protocol modified from Rayport et al. (1992). The procedure for isolation and growth was as described by Fog et al. (2006), except that neurons were plated at a density of 110,000 cells $/ \mathrm{cm}^{2}$ in either 24 or 48 -well multidishes according to the experiment conducted.

\subsection{Lentiviral vector construction and lentivirus production}

4.3.1. Construction of lentiviral vectors for virus-mediated VMAT2 overexpression

The lentiviral transfer vector, $\mathrm{pHsCXW}$, used for transgene delivery throughout this study is an improved and trimmed version of the pHR viral transfer vector originally generated by Naldini et al. (1996a,b). By insertion of a polylinker harboring unique restriction sites together with a marked size reduction (from $12 \mathrm{~kb}$ to $7 \mathrm{~kb}$ ), Leander Johansen et al. (2005) generated a viral transfer vector allowing for easier cloning of the transgene of interest without negative effects on viral titer and transduction efficiency in vitro and in vivo (GenBank accession no. AY468486). To generate pHs.CMV-hVMAT2, human VMAT2 cDNA (2908 bp, GenBank accession no. BC108927) was subcloned from the pciNeo-hVMAT2 construct into the SalI/XhoI site of pHsCXW. In order to replace the cytomegalovirus (CMV) promoter with the neuronal-specific
Synapsin I (1.1 kb, abbreviated as Syn) promoter, the promoter sequence was released from the parental construct (a kind gift from Dr. P. Osten; Dittgen et al., 2004) by ClaI/BamHI restriction digest and the Synapsin promoter inserted into pHs.CMVhVMAT2 using the same restriction sites. This virus was labeled LV-Syn-hVMAT2. A control lentiviral vector containing enhanced green fluorescent protein (EGFP) under the control of the Synapsin I promoter, LV-Syn-EGFP, was used as a control for all lentiviral-mediated overexpression experiments.

Lentiviral vector based RNAi was used to silence endogenous rVMAT2 activity in primary rat dopaminergic neurons. The dual lentiviral $p H s$-H1-shVMAT2-CMV-EGFP shRNA expression vector (named LV-siVMAT2-EGFP for simplicity) was generated by modifying the lentiviral backbone derived from the $\mathrm{pHsCXW}$ lentiviral transfer vector to allow the insertion of the dual cassette pHs-H1-shVMAT2-CMV-EGFP co-expressing EGFP as a reporter gene and rVMAT2 shRNA under the control of CMV and human H1 promoters, respectively. The 19nucleotide target sequences for shRNA-mediated rat VMAT2 (GenBank accession no.L00603) knockdown were selected by algorithms made public available by MWG-BIOTECH (MWGBIOTECH Inc., NC, USA) and Dharmacon (USA). All selected siRNA sequences were submitted to a BLAST search to ensure that siRNA duplexes were specifically directed against VMAT2 in order to minimize potential off-target effects. For each mRNA targeting sequence tested, four forward and reverse oligomers that included $5^{\prime} / 3^{\prime}$-sequences specifying BamHI/ MluI recognition sites were synthesized (TAG Copenhagen A/S, Denmark). The oligomers were annealed ( $25 \mu \mathrm{M}$ final concentration each) in $1 \times$ Taq buffer at $90^{\circ} \mathrm{C}$ for 5 min followed by cooling to RT. The insert solution was diluted 1:100 before ligation into the lentiviral backbone construct previously treated with BamHI/MluI. Recombinant colonies were identified by PCR and the dual LV pHs.H1-shVMAT2-CMV-EGFP shRNA expression vector plasmid obtained from a miniprep was sequenced. Among the mRNA target sequences tested, the selected siRNA sequence targeted rat VMAT2 mRNA sequence at positions $220-238$ relative to the first nucleotide (nt) of the start codon. A scrambled RNA sequence (5'-ttctccgaacgtgtcacgt-3') suggested by QIAGEN A/S (QIAGEN, VWR Aps, Denmark) was used as negative control in each experiment to verify the specificity of the siRNA sequences targeting only VMAT2 mRNA. The scrambled sequence, when analyzed using a BLAST search (NCBI, GenBank), showed no significant similarity to rat, mouse or human genes. For preparation of plasmid DNA, enriched LB/Ampicillin medium was inoculated with recombinant Escherichia coli strain, XLBlue, and incubated overnight at $37^{\circ} \mathrm{C}$. The next day, the DNA was extracted from $100 \mathrm{ml}$ of these cultures using the QIAGEN maxi-prep DNA kit according to the manufacturer's recommendations (QIAGEN, VWR Aps, Denmark).

4.3.2. Recombinant lentivirus production, titer estimation and cell transduction

Recombinant self-inactivating (SIN) lentiviral vectors were produced by transient transfection of the packaging cell line human embryonic kidney (HEK) 293T using a three-plasmid vector system modified from Naldini et al. (1996a) and optimized by Leander Johansen and colleagues (2005). Three 
days before transient cell transfection, HEK293T cells were seeded in large culture flasks with DMEM+10\% HI-FCS + PenStrep. On Day 1 of virion packaging, $5 \times 10^{6}$ cells were transiently transfected with $15 \mu \mathrm{g}$ total of DNA using Lipofectamine 2000. In one tube, $7 \mu \mathrm{g}$ of viral transfer plasmid together with $5 \mu$ g packaging plasmid pBR $\Delta 8.91$ (Zufferey et al., 1997) and $3 \mu \mathrm{g}$ of pMDG (Naldini et al., 1996a) to provide the vesicular stomatitis virus glycoprotein (VSV-G) envelope were diluted in a total volume of $1 \mathrm{ml}$ of OPTI-MEM®. In a separate tube, $30 \mu$ l of Lipofectamine 2000 was diluted in $1 \mathrm{ml}$ OPTI$M E M \circledast$. Both tubes were incubated separately for $5 \mathrm{~min}$ at RT before mixing and incubating for an additional $20 \mathrm{~min}$ at RT allowing the Lipofectamine-DNA-complexes to form. The Lipofectamine-DNA-complexes were transferred to a $20 \mathrm{mg} / \mathrm{L}$ poly-D-lysine coated T75 culture flask containing $5 \mathrm{ml}$ medium (DMEM+10\% HI-FCS without PenStrep) and $5 \mathrm{ml}$ $293 \mathrm{~T}$ cell suspension $\left(6 \times 10^{6}\right.$ cells). After an overnight incubation, the medium was replaced with DMEM containing $10 \% \mathrm{HI}-$ FCS and 1\% PenStrep. Virions released into the medium were collected on day 2 and day 3 post-transfection. The supernatant was collected 2 days post-transfection and stored at $4{ }^{\circ} \mathrm{C}$ until the last harvest 3 days post-transfection. Pooled supernatants were filtered by slow-speed centrifugation through a $0.45-\mu \mathrm{m}$ pore size filter before up-concentration by ultracentrifugation (Sorvall ultrancentrifuge, AH-629 swinging-bucket rotor) at $70,000 \times g$ for $2 \mathrm{~h}$. The virus pellet was dissolved in $200 \mu \mathrm{l}$ MEM (Sigma, M2279), aliquoted and frozen at $-80{ }^{\circ} \mathrm{C}$ until use. Lentiviral functional titers were determined using Roche reverse transcriptase (RT) assay reaction Kit (Roche, Cat. No. 11828657 910) in order to estimate retroviral propagation. Titer for lentiviral vectors were expressed as transducing units (TU) per $\mathrm{ml}$ being in the range of $8 \times 10^{7} \mathrm{TU} / \mathrm{ml}$ to $2 \times 10^{8} \mathrm{TU} / \mathrm{ml}$. The optimal multiplicity of infection (MOI), i.e. the number of transducing lentiviral particles per cell, was estimated using serial dilutions of lentiviral supernatant and determine number of infected cells.

Primary postnatal rat VM cultures were transduced after 5 days in vitro by incubation for $5 \mathrm{~h}$ in a minimal volume of conditioned neuronal medium with an $\mathrm{MOI}=8$ of experimental or control recombinant infectious lentiviral particles. At the end of this period, $\sim 75 \%$ of the media was replaced by a mix of conditioned and fresh neuronal SF1C medium supplemented with $10 \mathrm{ng} / \mathrm{ml}$ human recombinant GDNF (Chemicon, GF030) and an $\mathrm{MOI}=0.5$ recombinant infectious lentiviral particles. Cells were incubated for 10 additional days before experimentation without replacement of medium and experiments conducted, typically, on DIV15.

Immunocytochemistry was used to observe differences in cellular expression of VMAT2 after VMAT2 overexpression/ downregulation and to identify specific subset of cells expressing the recombinant lentiviral constructs. Cells were fixed in $4 \%$ paraformaldehyde for $20 \mathrm{~min}$ at $37{ }^{\circ} \mathrm{C}$ followed by rinsing 3 times in PBS and blocking with $5 \%$ goat serum (GS) dissolved in $0.03 \%$ Triton $\mathrm{X}-100 / \mathrm{PBS}$ buffer for $1 \mathrm{~h}$ at RT. Incubation with one or more of the following primary antibodies was performed: rabbit anti-human VMAT2 C-terminal (1:1000, Pel-Freez Rogers, Arkansas), mouse anti-mouse NeuN (1:100, Chemicon International), mouse anti-rat TH (1:1000, Chemicon International). All antibodies were dissolved in $0.3 \%$ Triton X-100/PBS buffer and incubations performed overnight at $4{ }^{\circ} \mathrm{C}$. Cells were rinsed $3 \times 10 \mathrm{~min}$ in $\mathrm{PBS}$ buffer before incubation with the appropriate secondary AlexaFlour 488/594-coupled goat antimouse/rabbit antibodies (Molecular Probes) diluted 1:200 in $0.03 \%$ Triton X-100/PBS buffer for $1 \mathrm{~h}$ at RT. Cells were rinsed 3 times in PBS. The fluorescent nuclear dye Hoechst $33342(1 \mu \mathrm{g} /$ $\mathrm{ml}$ ) was added during the next to last rinsing step, for $20 \mathrm{~min}$, and cells were visualized with a fluorescence microscope. Images were acquired using MetaMorph software version 5.0.

Western blotting was used to determine the protein levels of VMAT2 after VMAT2 overexpression/downregulation. Cells were rinsed twice in cold PBS and then once in PBS containing 12.5 mM N-ethylmaleimide (NEM, Sigma, N9125) before being hypotonically lysed in $2 \mathrm{mM}$ HEPES/2 mM EDTA in $\mathrm{mQH}_{2} \mathrm{O}$ with $1 \times$ complete protease inhibitors (Roche Diagnostics) for 2 min on ice. Primary cultures seeded in 24-well plates were lysed in $50 \mu \mathrm{l}$ hypotonic buffer and 4 wells were pooled per condition. The lysate was passed 10 times through a 26-G needle, then 5 times through a $30-\mathrm{G}$ needle before the nuclear fraction was spun down at $800 \times \mathrm{g}$ for $10 \mathrm{~min}$ at $4{ }^{\circ} \mathrm{C}$. The supernatant (cytoplasm and membranes) was transferred to a new tube and a $1 \%$ final concentration of SDS was added. Protein concentration was determined using the bicinchoninic acid (BCA) Protein Assay kit from Pierce (Rockford, IL). Equal amounts of protein (8-15 $\mu \mathrm{g})$ were loaded per well after addition of $4 \times \mathrm{Nu}-\mathrm{PAGE}$ sample buffer containing a reducing agent ( $4 \% \beta$-mercaptoethanol) and heating for $10 \mathrm{~min}$ at $55^{\circ} \mathrm{C}$. Proteins were electrophoresed on a $4-12 \%$ Bis-Tris Nu-Page gradient gel (Invitrogen) using MOPS SDS NP001 running buffer for $1 \mathrm{~h} 45 \mathrm{~min}$ at $150 \mathrm{~V}$. Proteins were transferred onto a methanol activated PVDF membrane (Immobilin-P; Millipore, Glostrup, Denmark) using an XCell II blot module (Invitrogen) at $30 \mathrm{~V}$ for $1 \mathrm{~h} 20 \mathrm{~min}$ in NuPAGE transfer buffer containing 10\% methanol. After the transfer of proteins, membranes were washed briefly in PBS and blocked in 5\% milk in PBS containing $0.1 \%$ Tween (PBS-T) for $1 \mathrm{~h}$. Membranes were incubated overnight at $4{ }^{\circ} \mathrm{C}$ with primary antibody (rabbit anti-human VMAT2 C-terminal (1:500, Pel-Freez Rogers, Arkansas), mouse anti-rat TH (1:1000, Chemicon International) or mouse antihuman GAPDH (1:5000, Abcam) dissolved in 5\% milk in PBS-T. After washing $3 \times 10 \mathrm{~min}$ in PBS-T membranes were incubated with the appropriate horseradish peroxidase (HRP)-conjugated secondary antibodies for $1 \mathrm{~h}$ at RT. Membranes were washed again $3 \times 10 \mathrm{~min}$ and developed using either the enhanced chemiluminescence (ECL) kit or the ECL-Plus kit from Amersham (Amersham Biosciences, Arlington Heights, IL). For protein band detection, film from Amersham was applied. Band size was estimated on the basis of the See-BluePlus2 pre-stained protein marker (Amersham Biosciences, RPN800) included on all blots. When different antigens had to be detected on the same membrane, this was stripped in $10 \%$ SDS, $1 \mathrm{M}$ Tris-HCl, $0.7 \% \beta$-mercaptoethanol at $55^{\circ} \mathrm{C}$ for $20 \mathrm{~min}$ followed by washing $3 \times 10 \mathrm{~min}$ in $\mathrm{PBS}$ and visualization as described above.

\subsection{Cell viability assays}

\subsubsection{MTT reduction}

PC12 cells were plated and transfected as described above. On day 3 post-transfection the cells were treated with various concentrations of METH for 4-5 days before cell viability was 
determined. To determine cell viability, cells were incubated with $0.5 \mathrm{mg} / \mathrm{ml} \mathrm{MTT}$ in the medium for $1 \mathrm{~h}$. At this point, the supernatant was removed and cells were lysed with $95 \%$ isopropanol/5\% acetic acid for $5 \mathrm{~min}$ on a rotational shake board (300 rounds per minute). An aliquot was transferred to a 96-well plate, and the optical density was measured using a Multiscan Ascent spectrophotometer equipped with Ascent software version 2.4 .2 (570 nm/690 nm filter pair). Data are expressed as mean \pm SEM of quadruplicate determinations and are shown as a percentage of respective untreated control cultures within each group.

\subsubsection{Calcein-AM staining}

Calcein-acetoxymethyl ester (Calcein AM; Molecular Probes) was used to identify living cells on basis of cell membrane integrity at the single cell level. PC12 cells, plated in differentiation media as indicated above, were incubated with $1 \mu \mathrm{M}$ Calcein $\mathrm{AM}$ for $10 \mathrm{~min}$ at $37^{\circ} \mathrm{C}$. The average fluorescence intensity from Calcein AM-positive cells (with a fluorescence threshold $>2000$ ) was estimated using the Target Activation BioApplication in a Cellomics ArrayScan highcontent screening automated microscope. Data are expressed as mean \pm SEM of quadruplicate determinations shown as a percentage of respective untreated control cultures within each group.

Quantitative analysis of neurite mass after silencing of endogenous VMAT2 gene was performed using a Cellomics ArrayScan HCS System. Cells were plated at 110,000 cells $/ \mathrm{cm}^{2}$ in 48-well multidishes, exposed to viral infection as described above and effect on neurite mass analyzed at DIV21. Cells were fixed with $4 \%$ fresh PFA and processed for TH immunocytochemistry using an Alexa Fluor 594-coupled secondary antibody and Hoechst 33342. Fluorescence was quantified using the GPCR BioApplication from Cellomics, which can automatically subtract the fluorescence intensity of the cell body from the total fluorescence signal of the field being imaged to yield the neuritic intensity only. The size of the cell body was estimated using a modified mask (nuclear diameter plus $2 \mu \mathrm{M}$ ) of the nucleus of the neuron, which was defined by Hoechst 33342-positive pixels. In this way also total number of cells per counted field was estimated. Twenty fields/well were captured using a $10 \times$ lens. The "neurite mass" of these 20 fields was then averaged and normalized to total number of cells per well. Each condition was as a minimum run in quadruplicates. After the Cellomics measurements, the total number of TH-positive cell bodies per well was counted by a blinded observer.

4.4.3. Dopamine release experiments-measurement of dopamine release and content by high-performance liquid chromatography coupled to electrochemical detection (HPLC-EC) PC12 cells were plated in proliferation medium and transfected as described above. The assay for dopamine release was performed 48-72 $\mathrm{h}$ post-transfection using the following procedure: All serum-containing medium was removed, cells washed once and replaced with $400 \mu \mathrm{l}$ pre-warmed $\left(37^{\circ} \mathrm{C}\right)$ Lockes buffer (154 mM NaCl, $5.6 \mathrm{mM} \mathrm{KCl}, 1.0 \mathrm{mM} \mathrm{MgCl}$, $2.3 \mathrm{mM} \mathrm{CaCl}$, 8.6 mM HEPES pH 7.4, 5.6 mM glucose) $+10 \mu \mathrm{M}$ mazindol. In order to verify a VMAT1/2-dependent mechanism of $\mathrm{KCl}$-induced dopamine release, $10 \mu \mathrm{M}$ reserpine was also present in the Lockes buffer during equilibration. After
$15 \mathrm{~min}$ at $37^{\circ} \mathrm{C}, 5 \% \mathrm{CO}_{2}$, this buffer was replaced with $320 \mu \mathrm{l}$ fresh buffer containing $10 \mu \mathrm{M}$ mazindol and $10 \mu \mathrm{M}$ tetrabenazine (TBZ), a VMAT2 inhibitor, per well for estimation of baseline dopamine release. After either 2 or $15 \mathrm{~min}, 200 \mu \mathrm{l}$ of this buffer was collected and immediately after, $80 \mu$ l Lockes buffer high $\mathrm{KCl} 2.5 \times(20.8 \mathrm{mM} \mathrm{NaCl}, 138.8 \mathrm{mM} \mathrm{KCl}$ (final concentration $55 \mathrm{mM}$ ), $1.0 \mathrm{mM} \mathrm{MgCl}_{2}, 2.3 \mathrm{mM} \mathrm{CaCl}_{2}, 8.6 \mathrm{mM}$ HEPES pH 7.4, $5.6 \mathrm{mM}$ glucose, $10 \mu \mathrm{M}$ mazindol and $10 \mu \mathrm{M}$ reserpine (for relevant experiments) was added per well. After an additional 2 or $15 \mathrm{~min}$, the remaining $200 \mu$ l buffer was collected and used for measurement of KCl-stimulated dopamine release. During stimulation, the cells were kept either on a heating plate $\left(37^{\circ} \mathrm{C}\right)$ or transferred to a $5 \% \mathrm{CO}_{2}$, $37^{\circ} \mathrm{C}$ incubator. The sample buffer was collected into special filter tubes containing $0.1 \mathrm{M} \mathrm{HClO}_{4}$ and $100 \mu \mathrm{M}$ EDTA to minimize air oxidation of dopamine. Residual dopamine was collected immediately by adding $200 \mu \mathrm{l} 0.1 \mathrm{M} \mathrm{HClO}_{4}$ containing $0.01 \%$ L-cysteine, and $100 \mu \mathrm{M}$ EDTA to each well and lysing the cells by one cycle of freeze-thawing. All samples were kept on ice until filtering by spinning at $12,000 \times \mathrm{g}$ for $10 \mathrm{~min}$ using $0.45 \mu \mathrm{m}$ filters. The dopamine samples were then frozen at $-80{ }^{\circ} \mathrm{C}$ until measurement using HPLC-EC after dilution 5-10x for basal release samples and 20-40x for potassium stimulation samples. In a separate dish, the viability of transfected cells corresponding to each transfection condition was estimated using the MTT reduction assay as described above. All data are expressed as the mean \pm SEM of quadruplicate determinations and dopamine levels (pmol) are normalized to MTT reduction (random OD units) to exclude potential transfection-mediated toxicity from affecting our interpretation of the HPLC results.

Postnatal neuronal dopaminergic cultures (110,000 cells/ $\mathrm{cm}^{2}$ ) were seeded on 24-well plates containing an $80 \%$ confluent monolayer of glial cells and transduced as described previously. On day 10 post-lentiviral transduction (DIV15), baseline and stimulated dopamine release after 2 and $15 \mathrm{~min}$ was estimated in the same set of cells using the same procedure as that described for PC12 cell measurements except that $10 \mu \mathrm{M}$ TBZ was added instead of reserpine. Residual dopamine was measured by adding $200 \mu \mathrm{l} 0.1 \mathrm{M}$ $\mathrm{HClO}_{4}$ containing $0.01 \%$ L-cysteine and $100 \mu \mathrm{M}$ EDTA to each well and lysing the cells by freeze-thawing after high $\mathrm{KCl}$ exposure. The cells having been exposed to high $\mathrm{KCl}$ for $2 \mathrm{~min}$ were lysed immediately and VMAT2 and TH protein levels in the different conditions were estimated by Western blotting. The absolute dopamine concentration (pmol) measured by HPLC-EC was standardized first to the volume of buffer to collect the samples, sample dilution (typically 5-10x for basal release, 20-40x for stimulated release, and 60-100x for intracellular dopamine), and then to the levels of $\mathrm{TH}$ protein as estimated by densitometry of TH western blots. All data are expressed as a mean \pm SEM of three independent experiments.

To measure the absolute concentration of dopamine in the cell culture samples collected, samples were typically diluted 60-100x, and a sample volume of $20 \mu \mathrm{l}$ was injected into an Antec Decade II electrochemical detector using a prodigy $3 \mathrm{u}$ ODS(3) 100A column (Phenomenex, UK) set at a potential of $800 \mathrm{mV}$ in relation to a Carbon flow cell with a $\mathrm{KCl}$ reference electrode. The mobile phase was delivered by an Biolab HPLC pump at $0.3 \mathrm{ml} / \mathrm{min}$ and contained $0.051 \mathrm{M} \mathrm{NaH}_{2} \mathrm{PO}_{4} \cdot \mathrm{H}_{2} \mathrm{O}$ with $250 \mathrm{mg} / \mathrm{L}$ octanesulfonic acid, $20 \mathrm{mg} / \mathrm{L} \mathrm{Na}{ }_{2}$ EDTA and 7\% 
acetonitrile, adjusted to $\mathrm{pH} 3.6$ with $1 \mathrm{M}$ phosphoric acid and degassed. Data were acquired using the Chromeleon (Dionex, Denmark) software package. Dopamine was identified on the basis of retention time from known standards (Sigma, H-8502), and concentrations were calculated on the basis of a standard calibration curve ranging from 25 to $400 \mathrm{fmol} /$ injection volume. Before analysis, samples were diluted in buffer to stay within the range of the calibration curve. Assays were conducted in triplicate or quadruplicates.

4.4.4. Measurement of cytosolic dopamine using a digitonin permeabilization method

Primary rat postnatal VM cultures transduced for 10 days (as described above) were rinsed twice in PBS. Following a 15-min equilibration period at $37^{\circ} \mathrm{C}$ in Lockes buffer containing $10 \mu \mathrm{M}$ mazindol (to prevent reverse transport of dopamine), an aliquot of this buffer was collected to measure baseline dopamine release. To increase the concentration of cytosolic dopamine, cells were exposed to $10 \mu \mathrm{M}$ AMPH and $10 \mu \mathrm{M}$ mazindol dissolved in Lockes buffer for $10 \mathrm{~min}$ at $37^{\circ} \mathrm{C}$. This buffer was collected and the cells were immediately transferred to ice and exposed to Lockes buffer with or without $40 \mu \mathrm{g} / \mu \mathrm{l}$ digitonin containing $10 \mu \mathrm{M}$ mazindol and $0.01 \%$ L-cysteine for $7 \mathrm{~min}$ on ice, while gently rocking. The supernatant (cytosolic extract) was collected and divided into two aliquots for either measurement of dopamine concentration or for quantification of lactate dehydrogenase (LDH) activity to monitor membrane integrity.

The dopamine concentration in the supernatant was measured using a dopamine ELISA kit (RE59161, IBL, Hamburg, Germany). Using dopamine standards provided in the kit (12-2250 ng/mL dopamine), the cytoplasmic dopamine levels were in the range of $15-50 \mathrm{ng} / \mathrm{mL}$ depending on the experimental condition. To remove any impurities, $100 \mu \mathrm{l}$ of undiluted sample was first transferred to 0.2 um filter tubes, spun down for $10 \mathrm{~min}$ at $12,000 \times \mathrm{g}$ and an extraction method performed according to the manufacturer's instructions. The remainder of the dopamine ELISA procedure was conducted according to the protocol provided in the kit. All experimental buffers used for the different conditions were included as controls and did not give any background signal. Data are expressed as fmol dopamine and differences in absolute values compared to HPLC-EC determinations reflect differences in sample volume collection and dilution needed for each analysis method. To monitor the extent of plasma membrane rupture, LDH activity was measured using the following procedure: A $10-\mu l$ aliquot from all samples was transferred to a 96-well plate. Chilled KPP-buffer $(40.34 \mathrm{mM}$ $\mathrm{K}_{2} \mathrm{HPO}_{4} \times 3 \mathrm{H}_{2} \mathrm{O}$ and $9.70 \mathrm{mM} \mathrm{KH_{2 }} \mathrm{PO}_{4}$ in $\mathrm{dH}_{2} \mathrm{O}, \mathrm{pH}$ 7.5)/pyruvate was mixed with $1 \% \mathrm{NaHCO}_{3}$-buffer/NADH at a ratio of $50: 1$ and $200 \mu \mathrm{l}$ of this mixture added to each sample. Using a Multiscan Ascent spectrophotometer equipped with Ascent software version 2.4.2 (340 nm filter pair), the kinetic NADH absorbance was measured during a 20-min interval and graphed as a function of different digitonin concentrations. Residual, intracellular dopamine levels were extracted by freeze-thawing cells in $200 \mu \mathrm{l} 0.1 \mathrm{M} \mathrm{HClO}_{4}$ containing $0.01 \%$ L-cysteine and measured by dopamine ELISA after the digitonin extraction to ensure that vesicular membranes had not been ruptured.

\subsubsection{Statistics}

All experiments are displayed as means of triplicates or quadruplicates \pm standard errors of the mean (SEM). Oneway analysis of variance (ANOVA) and post hoc Student's ttests were used for statistical evaluation using the statistical software [GraphPad (San Diego, CA) Prism Software].

\section{Acknowledgments}

The authors would like to thank Dr. Jeff Erickson for providing the pciNeoVMAT2 plasmid, Lone Lind for her excellent technical assistance, Dr. Arne Mørk for his invaluable assistance with the HPLC measurements and Dr. Jan Egebjerg for critical comments on the manuscript.

\section{R E F E R E N C E S}

Asanuma, M., Miyazaki, I., Ogawa, N., 2003. Dopamine- or L-DOPA-induced neurotoxicity: the role of dopamine quinone formation and tyrosinase in a model of Parkinson's disease. Neurotox. Res. 5, 165-176.

Bader, M.F., Holz, R.W., Kumakura, K., Vitale, N., 2002. Exocytosis: the chromaffin cell as a model system. Ann. N.Y. Acad. Sci. 971, 178-183.

Barzilai, A., Melamed, E., Shirvan, A., 2001. Is there a rationale for neuroprotection against dopamine toxicity in Parkinson's disease? Cell Mol. Neurobiol. 21, 215-235.

Berman, S.B., Hastings, T.G., 1999. Dopamine oxidation alters mitochondrial respiration and induces permeability transition in brain mitochondria: implications for Parkinson's disease. J. Neurochem. 73, 1127-1137.

Blum, D., Torch, S., Lambeng, N., Nissou, M., Benabid, A.L., Sadoul, R., Verna, J.M., 2001. Molecular pathways involved in the neurotoxicity of 6-OHDA, dopamine and MPTP: contribution to the apoptotic theory in Parkinson's disease. Prog. Neurobiol. 65, 135-172.

Caudle, W.M., Richardson, J.R., Wang, M.Z., Taylor, T.N., Guillot, T.S., Mccormack, A.L., Colebrooke, R.E., Di Monte, D.A., Emson, P.C., Miller, G.W., 2007. Reduced vesicular storage of dopamine causes progressive nigrostriatal neurodegeneration. J. Neurosci. 27, 8138-8148.

Chen, C.X., Huang, S.Y., Zhang, L., Liu, Y.J., 2005. Synaptophysin enhances the neuroprotection of VMAT2 in MPP+-induced toxicity in MN9D cells. Neurobiol. Dis. 19, 419-426.

Choi, H.J., Lee, S.Y., Cho, Y., Hwang, O., 2005. Inhibition of vesicular monoamine transporter enhances vulnerability of dopaminergic cells: relevance to Parkinson's disease. Neurochem. Int. 46, 329-335.

Colebrooke, R.E., Humby, T., Lynch, P.J., Mcgowan, D.P., Xia, J., Emson, P.C., 2006. Age-related decline in striatal dopamine content and motor performance occurs in the absence of nigral cell loss in a genetic mouse model of Parkinson's disease. Eur. J. Neurosci. 24, 2622-2630.

Conway, K.A., Rochet, J.C., Bieganski, R.M., Lansbury Jr., P.T., 2001. Kinetic stabilization of the alpha-synuclein protofibril by a dopamine-alpha-synuclein adduct. Science 294, 1346-1349.

Cubells, J.F., Rayport, S., Rajendran, G., Sulzer, D., 1994. Methamphetamine neurotoxicity involves vacuolation of endocytic organelles and dopamine-dependent intracellular oxidative stress. J. Neurosci. 14, 2260-2271.

Dittgen, T., Nimmerjahn, A., Komai, S., Licznerski, P., Waters, J., Margrie, T.W., Helmchen, F., Denk, W., Brecht, M., Osten, P., 
2004. Lentivirus-based genetic manipulations of cortical neurons and their optical and electrophysiological monitoring in vivo. Proc. Natl. Acad. Sci. U. S. A. 101, 18206-18211.

Egashira, T., Yamanaka, Y., 1993. Changes in monoamine oxidase activity in mouse brain associated with d-methamphetamine dependence and withdrawal. Biochem. Pharmacol. 46, 609-614.

Eisenhofer, G., Kopin, I.J., Goldstein, D.S., 2004. Leaky catecholamine stores: undue waste or a stress response coping mechanism? Ann. N.Y. Acad. Sci. 1018, 224-230.

Erickson, J.D., Eiden, L.E., 1993. Functional identification and molecular cloning of a human brain vesicle monoamine transporter. J. Neurochem. 61, 2314-2317.

Erickson, J.D., Eiden, L.E., Hoffman, B.J., 1992. Expression cloning of a reserpine-sensitive vesicular monoamine transporter. Proc. Natl. Acad. Sci. U. S. A. 89, 10993-10997.

Fiskum, G., Craig, S.W., Decker, G.L., Lehninger, A.L., 1980. The cytoskeleton of digitonin-treated rat hepatocytes. Proc. Natl. Acad. Sci. U. S. A. 77, 3430-3434.

Fog, J.U., Khoshbouei, H., Holy, M., Owens, W.A., Vaegter, C.B., Sen, N., Nikandrova, Y., Bowton, E., Mcmahon, D.G., Colbran, R.J., Daws, L.C., Sitte, H.H., Javitch, J.A., Galli, A., Gether, U., 2006. Calmodulin kinase II interacts with the dopamine transporter $\mathrm{C}$ terminus to regulate amphetamine-induced reverse transport. Neuron 51, 417-429.

Fon, E.A., Pothos, E.N., Sun, B.C., Killeen, N., Sulzer, D., Edwards, R.H., 1997. Vesicular transport regulates monoamine storage and release but is not essential for amphetamine action. Neuron 19, 1271-1283.

Fumagalli, F., Gainetdinov, R.R., Wang, Y.M., Valenzano, K.J., Miller, G.W., Caron, M.G., 1999. Increased methamphetamine neurotoxicity in heterozygous vesicular monoamine transporter 2 knock-out mice. J. Neurosci. 19, 2424-2431.

Gainetdinov, R.R., Fumagalli, F., Wang, Y.M., Jones, S.R., Levey, A.I., Miller, G.W., Caron, M.G., 1998. Increased MPTP neurotoxicity in vesicular monoamine transporter 2 heterozygote knockout mice. J. Neurochem. 70, 1973-1978.

Gandhi, S., Wood, N.W., 2005. Molecular pathogenesis of Parkinson's disease. Hum. Mol. Genet. 14 (Spec No. 2), 2749-2755.

Glatt, C.E., Wahner, A.D., White, D.J., Ruiz-Linares, A., Ritz, B., 2006. Gain-of-function haplotypes in the vesicular monoamine transporter promoter are protective for Parkinson disease in women. Hum. Mol. Genet. 15, 299-305.

Graham, D.G., Tiffany, S.M., Bell Jr., W.R., Gutknecht, W.F., 1978. Autoxidation versus covalent binding of quinones as the mechanism of toxicity of dopamine, 6-hydroxydopamine, and related compounds toward C1300 neuroblastoma cells in vitro. Mol. Pharmacol. 14, 644-653.

Holtje, M., Von Jagow, B., Pahner, I., Lautenschlager, M., Hortnagl, H., Nurnberg, B., Jahn, R., Ahnert-Hilger, G., 2000. The Neuronal monoamine transporter VMAT2 is regulated by the trimeric GTPase Go(2). J. Neurosci. 20, 2131-2141.

Holtje, M., Winter, S., Walther, D., Pahner, I., Hortnagl, H., Ottersen, O.P., Bader, M., Ahnert-Hilger, G., 2003. The vesicular monoamine content regulates VMAT2 activity through Galphaq in mouse platelets. Evidence for autoregulation of vesicular transmitter uptake. J. Biol. Chem. 278, 15850-15858.

Johnston, T.H., Brotchie, J.M., 2006. Drugs in development for Parkinson's disease: an update. Curr. Opin. Investig. Drugs 7, 25-32.

Jones, S.R., Joseph, J.D., Barak, L.S., Caron, M.G., Wightman, R.M., 1999. Dopamine neuronal transport kinetics and effects of amphetamine. J. Neurochem. 73, 2406-2414.

Larsen, K.E., Fon, E.A., Hastings, T.G., Edwards, R.H., Sulzer, D., 2002. Methamphetamine-induced degeneration of dopaminergic Neurons involves autophagy and upregulation of dopamine synthesis. J. Neurosci. 22, 8951-8960.
Lavoie, M.J., Hastings, T.G., 1999. Dopamine quinone formation and protein modification associated with the striatal neurotoxicity of methamphetamine: evidence against a role for extracellular dopamine. J. Neurosci. 19, 1484-1491.

Lavoie, M.J., Ostaszewski, B.L., Weihofen, A., Schlossmacher, M.G., Selkoe, D.J., 2005. Dopamine covalently modifies and functionally inactivates parkin. Nat. Med. 11, 1214-1221.

Leander Johansen, J., Dago, L., Tornoe, J., Rosenblad, C., Kusk, P., 2005. A new versatile and compact lentiviral vector. Mol. Biotechnol. 29, 47-56.

Leviel, V., 2001. The reverse transport of DA, what physiological significance? Neurochem. Int. 38, 83-106.

Liu, Y., Edwards, R.H., 1997. The role of vesicular transport proteins in synaptic transmission and neural degeneration. Annu. Rev. Neurosci. 20, 125-156.

Liu, Y., Peter, D., Roghani, A., Schuldiner, S., Prive, G.G., Eisenberg, D., Brecha, N., Edwards, R.H., 1992. A cDNA that suppresses MPP+ toxicity encodes a vesicular amine transporter. Cell 70, 539-551.

Lotharius, J., Brundin, P., 2002. Impaired dopamine storage resulting from alpha-synuclein mutations may contribute to the pathogenesis of Parkinson's disease. Hum. Mol. Genet. 11, 2395-2407.

Lotharius, J., O'malley, K.L., 2000. The parkinsonism-inducing drug 1-methyl-4-phenylpyridinium triggers intracellular dopamine oxidation. A novel mechanism of toxicity. J. Biol. Chem. 275, 38581-38588.

Lotharius, J., O'malley, K.L., 2001. Role of mitochondrial dysfunction and dopamine-dependent oxidative stress in amphetamine-induced toxicity. Ann. Neurol. 49, 79-89.

Lotharius, J., Barg, S., Wiekop, P., Lundberg, C., Raymon, H.K., Brundin, P., 2002. Effect of mutant alpha-synuclein on dopamine homeostasis in a new human mesencephalic cell line. J. Biol. Chem. 277, 38884-38894.

Lotharius, J., Falsig, J., Van Beek, J., Payne, S., Dringen, R., Brundin, P., Leist, M., 2005. Progressive degeneration of human mesencephalic neuron-derived cells triggered by dopamine-dependent oxidative stress is dependent on the mixed-lineage kinase pathway. J. Neurosci. 25, 6329-6342.

Miller, G.W., Erickson, J.D., Perez, J.T., Penland, S.N., Mash, D.C., Rye, D.B., Levey, A.I., 1999. Immunochemical analysis of vesicular monoamine transporter (VMAT2) protein in Parkinson's disease. Exp. Neurol. 156, 138-148.

Miyazaki, I., Asanuma, M., Diaz-Corrales, F.J., Fukuda, M., Kitaichi, K., Miyoshi, K., Ogawa, N., 2006. Methamphetamine-induced dopaminergic neurotoxicity is regulated by quinone formation-related molecules. FASEB J. 20, 571-573.

Mooslehner, K.A., Chan, P.M., Xu, W., Liu, L., Smadja, C., Humby, T., Allen, N.D., Wilkinson, L.S., Emson, P.C., 2001. Mice with very low expression of the vesicular monoamine transporter 2 gene survive into adulthood: potential mouse model for parkinsonism. Mol. Cell Biol. 21, 5321-5331.

Mosharov, E.V., Gong, L.W., Khanna, B., Sulzer, D., Lindau, M., 2003. Intracellular patch electrochemistry: regulation of cytosolic catecholamines in chromaffin cells. J. Neurosci. 23, 5835-5845.

Mosharov, E.V., Staal, R.G., Bove, J., Prou, D., Hananiya, A., Markov, D., Poulsen, N., Larsen, K.E., Moore, C.M., Troyer, M.D., Edwards, R.H., Przedborski, S., Sulzer, D., 2006. Alpha-synuclein overexpression increases cytosolic catecholamine concentration. J. Neurosci. 26, 9304-9311.

Mundorf, M.L., Hochstetler, S.E., Wightman, R.M., 1999. Amine weak bases disrupt vesicular storage and promote exocytosis in chromaffin cells. J. Neurochem. 73, 2397-2405.

Naldini, L., Blomer, U., Gage, F.H., Trono, D., Verma, I.M., 1996a. Efficient transfer, integration, and sustained long-term expression of the transgene in adult rat brains injected with a lentiviral vector. Proc. Natl. Acad. Sci. U. S. A. 93, 11382-11388. 
Naldini, L., Blomer, U., Gallay, P., Ory, D., Mulligan, R., Gage, F.H., Verma, I.M., Trono, D., 1996b. In vivo gene delivery and stable transduction of nondividing cells by a lentiviral vector. Science 272, 263-267.

Pothos, E.N., 2002. Regulation of dopamine quantal size in midbrain and hippocampal neurons. Behav. Brain Res. 130, 203-207.

Pothos, E.N., Larsen, K.E., Krantz, D.E., Liu, Y., Haycock, J.W., Setlik, W., Gershon, M.D., Edwards, R.H., Sulzer, D., 2000. Synaptic vesicle transporter expression regulates vesicle phenotype and quantal size. J. Neurosci. 20, 7297-7306.

Rayport, S., Sulzer, D., Shi, W.X., Sawasdikosol, S., Monaco, J., Batson, D., Rajendran, G., 1992. Identified postnatal mesolimbic dopamine neurons in culture: morphology and electrophysiology. J. Neurosci. 12, 4264-4280.

Rochet, J.C., Outeiro, T.F., Conway, K.A., Ding, T.T., Volles, M.J., Lashuel, H.A., Bieganski, R.M., Lindquist, S.L., Lansbury, P.T., 2004. Interactions among alpha-synuclein, dopamine, and biomembranes: some clues for understanding neurodegeneration in Parkinson's disease. J. Mol. Neurosci. 23, 23-34.

Schuldiner, S., 1994. A molecular glimpse of vesicular monoamine transporters. J. Neurochem. 62, 2067-2078.

Stankovski, L., Alvarez, C., Ouimet, T., Vitalis, T., El-Hachimi, K.H., Price, D., Deneris, E., Gaspar, P., Cases, O., 2007. Developmental cell death is enhanced in the cerebral cortex of mice lacking the brain vesicular monoamine transporter. J. Neurosci. 27, 1315-1324.
Sulzer, D., 2001. alpha-Synuclein and cytosolic dopamine: stabilizing a bad situation. Nat. Med. 7, 1280-1282.

Sulzer, D., Chen, T.K., Lau, Y.Y., Kristensen, H., Rayport, S., Ewing, A., 1995. Amphetamine redistributes dopamine from synaptic vesicles to the cytosol and promotes reverse transport. J. Neurosci. 15, 4102-4108.

Takahashi, N., Miner, L.L., Sora, I., Ujike, H., Revay, R.S., Kostic, V., Jackson-Lewis, V., Przedborski, S., Uhl, G.R., 1997. VMAT2 knockout mice: heterozygotes display reduced amphetamine-conditioned reward, enhanced amphetamine locomotion, and enhanced MPTP toxicity. Proc. Natl. Acad. Sci. U. S. A. 94, 9938-9943.

Weingarten, P., Bermak, J., Zhou, Q.Y., 2001. Evidence for non-oxidative dopamine cytotoxicity: potent activation of NF-kappa B and lack of protection by anti-oxidants. J. Neurochem. 76, 1794-1804.

Xu, J., Kao, S.Y., Lee, F.J., Song, W., Jin, L.W., Yankner, B.A., 2002. Dopamine-dependent neurotoxicity of alpha-synuclein: a mechanism for selective neurodegeneration in Parkinson disease. Nat. Med. 8, 600-606.

Zheng, G., Dwoskin, L., Crooks, P., 2006. Vesicular monoamine transporter 2: role as a novel target for drug development. AAPS J. 8, E682-E692.

Zufferey, R., Nagy, D., Mandel, R.J., Naldini, L., Trono, D., 1997. Multiply attenuated lentiviral vector achieves efficient gene delivery in vivo. Nat. Biotechnol. 15, 871-875. 